\title{
Characteristics of Chinese herbal medicine usage in ischemic heart disease patients among type 2 diabetes and their protection against hydrogen peroxide-mediated apoptosis in H9C2 cardiomyoblasts
}

\author{
Fuu-Jen Tsai ${ }^{1,2,3, *}$, Tsung-Jung Ho ${ }^{1,4,5, *}$, Chi-Fung Cheng ${ }^{6}$, Yi-Tzone Shiao ${ }^{7}$, Wen-Kuei \\ Chien ${ }^{8}$, Jin-Hua Chen ${ }^{8,9}$, Xiang Liu ${ }^{10}$, Hsinyi Tsang ${ }^{10}$, Ting-Hsu Lin², Chiu-Chu Liao ${ }^{2}$, \\ Shao-Mei Huang ${ }^{2}$, Ju-Pi Li ${ }^{1,11}$, Cheng-Wen Lin ${ }^{12}$, Jaung-Geng Lin ${ }^{1}$, Yu-Ching Lan ${ }^{13}$, \\ Yu-Huei Liu ${ }^{2,14}$, Chien-Hui Hung ${ }^{15}$, Jung-Chun Lin ${ }^{16}$, Chih-Chien Lin ${ }^{17}$, Chih-Ho Lai ${ }^{18}$, \\ Wen-Miin Liang ${ }^{6}$, Ying-Ju Lin ${ }^{1,2}$ \\ ${ }^{1}$ School of Chinese Medicine, China Medical University, Taichung, Taiwan \\ ${ }^{2}$ Genetic Center, Department of Medical Research, China Medical University Hospital, Taichung, Taiwan \\ ${ }^{3}$ Department of Health and Nutrition Biotechnology, Asia University, Taichung, Taiwan \\ ${ }^{4}$ Division of Chinese Medicine, China Medical University Beigang Hospital, Yunlin County, Taiwan \\ ${ }^{5}$ Division of Chinese Medicine, Tainan Municipal An-Nan Hospital-China Medical University, Tainan, Taiwan \\ ${ }^{6}$ Graduate Institute of Biostatistics, School of Public Health, China Medical University, Taichung, Taiwan \\ ${ }^{7}$ Heart Center, China Medical University Hospital, Taichung, Taiwan \\ ${ }^{8}$ Biostatistics Center, College of Management, Taipei Medical University, Taipei, Taiwan \\ ${ }^{9}$ School of Health Care Administration, College of Management, Taipei Medical University, Taipei, Taiwan \\ ${ }^{10}$ National Institute of Allergy and Infectious Diseases, National Institutes of Health, Bethesda, Maryland, USA \\ ${ }^{11}$ Rheumatism Research Center, China Medical University Hospital, Taichung, Taiwan \\ ${ }^{12}$ Department of Medical Laboratory Science and Biotechnology, China Medical University, Taichung, Taiwan \\ ${ }^{13}$ Department of Health Risk Management, China Medical University, Taichung, Taiwan \\ ${ }^{14}$ Graduate Institute of Integrated Medicine, China Medical University, Taichung, Taiwan \\ ${ }^{15}$ Graduate Institute of Clinical Medical Science, Chang-Gung University, Taipei, Taiwan \\ ${ }^{16}$ School of Medical Laboratory Science and Biotechnology, College of Medical Science and Technology, Taipei Medical \\ University, Taipei, Taiwan \\ ${ }^{17}$ Department of Cosmetic Science, Providence University, Taichung, Taiwan \\ ${ }^{18}$ Department of Microbiology and Immunology, Chang Gung University, Taoyuan, Taiwan \\ *These authors have contributed equally to this work \\ Correspondence to: Ying-Ju Lin, email: yjlin.kath@gmail.com \\ Wen-Miin Liang, email:wmliang@mail.cmu.edu.tw
}

Keywords: type 2 diabetes, ischemic heart disease, Chinese herbal medicine, oxidative stress, cardiomyoblasts

Received: June 01, 2016

Accepted: December 27, 2016

Published: January 14, 2017

\section{ABSTRACT}

Evidence for long-term use of Chinese herbal medicine (CHM) as an adjuvant treatment in patients with type 2 diabetes (T2D) remains limited. This study aimed to assess the frequency of use, utilization patterns, and therapeutic effects of adjuvant CHM for ischemic heart disease (IHD) in patients with T2D in Taiwan. We identified 4620 IHD patients with T2D. After matching for age, gender, and insulin use, 988 subjects each were allocated to a CHM group and a non-CHM group. There were no differences in baseline characteristics except for comorbidities. The CHM group contained more cases with chronic obstructive pulmonary disease, hepatitis, ulcer disease, and hyperlipidemia. The cumulative survival probability was higher in CHM users than in matched non-CHM users aged 60 years or older $(P<.0001, \log$ 
rank test) regardless of gender $(P=.0046$ for men, $P=.0010$ for women, log rank test). Among the top 12 CHM combinations, Shu-Jing-Huo-Xue-Tang and Shao-YaoGan-Cao-Tang $(13.6 \%)$ were the most common. This dual combination improved antiapoptotic activity in $\mathrm{H}_{2} \mathrm{O}_{2}$-exposed $\mathrm{H} 9 \mathrm{C} 2$ cells by enhancing phosphorylation of glycogen synthase kinase-3 3 and p38 mitogen-activated protein kinase and could increase the survival of myocardial cells. Our study suggests that adjuvant CHM therapy may increase the survival probability and provides a comprehensive list for future investigations of the safety and efficacy of CHM for IHD patients with T2D.

\section{INTRODUCTION}

Type 2 diabetes (T2D) is a disorder of glucose metabolism that affects more than $6 \%$ of the population worldwide [1]. The prevalence of T2D has been steadily increasing in Asia [2], [3], [4]. T2D is regarded as glycemia resulting from impaired $\beta$-cell function, decreased insulin sensitivity in tissues, and increased glucose levels in the blood [5]. Diabetic complications including cardiovascular disease, retinopathy, nephropathy, neuropathy, and peripheral circulatory disorders are believed to be responsible for the symptoms, signs, ill-defined secondary conditions, and mortality observed in these patients [6], [7]. Cardiovascular disease is the major cause of morbidity and mortality in patients with diabetes. Overall, cardiovascular mortality has been declining during recent decades [8]. However, cardiovascular mortality among T2D patients has been increasing [6], suggesting that there are still unknown factors that contribute to the excess cardiovascular risk in these patients.

Chinese herbal medicine (CHM) was being used for the treatment of diabetes and its complications before the development of insulin [9], [10], [11]. In Taiwan, CHM is one of the important health care systems provided by the National Health Insurance program [12], [13]. The National Health Insurance database serves as a platform for studying the frequency of use, utilization patterns, and therapeutic effects of Chinese herbal therapies prescribed by licensed CHM practitioners in Taiwan. CHM prescribing patterns in Taiwan have been explored by population-based studies in several diseases, including childhood asthma [14], breast cancer [15], chronic kidney disease [16], diabetes [17], endometriosis [18], primary dysmenorrhea [19], and schizophrenia [20]. Blood glucose levels can be controlled by lifestyle modification [21] and treatment with hypoglycemic or anti-hyperglycemic, insulin-sensitizing, and insulin secretion-enhancing medications [22], [23], [24]. Increased cardiovascular risk and mortality has been reported in patients with diabetes using metformin, sulfonylureas, and thiazolidinediones [22], [23], [24], [25]. Long-term use of thiazolidinediones increases the risks of bone fracture, lower respiratory tract infection, and bladder cancer in patients with diabetes [22], [26], [27]. These reports have prompted a search for alternative and complementary therapies for better management of diabetes and its complications.
In this study, we used a population-based database to investigate demographic characteristics, overall survival, and CHM prescribing patterns for individuals with ischemic heart disease (IHD) complicating T2D. In addition, we evaluated the ability of a combination of herbal formulas and/or single herbs to protect cardiomyocytes in a hypoxic state.

\section{RESULTS}

\section{Characteristics of study patients}

A total of 4,620 patients diagnosed with IHD one year after diagnosis of diabetes were included in our study cohort (Figure 1). Of these, 1,274 (27.6\%) were in the CHM group and 3,346 (72.4\%) were in the nonCHM group. The characteristics of the CHM group versus the non-CHM group (all subjects) are shown in Table 1. Statistically significant differences were found for age, gender, time interval between diagnosis of diabetes and that of IHD, comorbidities (chronic obstructive pulmonary disease [COPD], hepatitis, ulcer disease, hyperlipidemia, and obesity), income, and urbanization level between the two groups $(P<.05)$. The CHM group contained more people who were younger, female, and had a longer time interval between diabetes and diagnosis of IHD, more cases of COPD, hepatitis, ulcer disease, hyperlipidemia, and obesity, more people with a higher income, and more urban dwellers. After matching the two groups for age, gender, and insulin use, frequency matched CHM and non-CHM users were compared (Table 1), and no differences were found in the distribution of baseline characteristics, except for comorbidities. There were significant differences in the frequency distributions for COPD, hepatitis, ulcer disease, and hyperlipidemia $(P<.05)$. Matched subjects in the CHM group were characterized by more cases of COPD, hepatitis, ulcer disease, and hyperlipidemia, suggesting that CHM users had more comorbidities.

\section{Survival analysis according to CHM use}

Figure $2 \mathrm{~A}$ shows the cumulative probability of survival after a diagnosis of IHD in subjects with a preexisting diagnosis of T2D according to use of CHM. Overall survival rate between matched CHM and nonCHM users differed $(P<.0001, \log$ rank test $)$. The 
cumulative survival probability was higher in CHM users than in matched non-CHM users. When the subjects were stratified according to age-younger than 60 years (Figure 2B) or 60 years or older (Figure 2C) - there were no significant differences in survival probabilities between matched CHM and non-CHM users ( $P=$ $.2260, \log$ rank test). However, the survival rates were significantly different between matched CHM and nonCHM users aged 60 years or older $(P<.0001$, log rank test). The cumulative probability of survival was higher in CHM users than in matched non-CHM users. When the subjects were stratified according to whether they were male (Figure 2D) or female (Figure 2E), survival rates were significantly different between matched CHM and non-CHM users for both men and women $(P=.0046$ and $P=.0010$, respectively, $\log$ rank test). The cumulative probability of survival was higher in CHM users than in matched non-CHM users.

With regard to mortality, significant differences in the protective effect of CHM were found when subjects were stratified by age, gender, and time interval between the diagnosis of diabetes and that of IHD (Figure 3). The subgroup analysis showed that use of CHM was associated with a protective effect in those who were aged 60 years or older (hazard ratio [HR] $0.40,95 \%$ confidence interval [CI] 0.27-0.59) in both men (HR 0.52, 95\% CI 0.33-0.80)

Patients with diagnosis of diabetes

Between January 1, 1996 and December 31,

2012

$(n=204,227)$

Patients with admitted for ischemic heart disease diagnosed date between January 1,

1999 and December 31, 2010

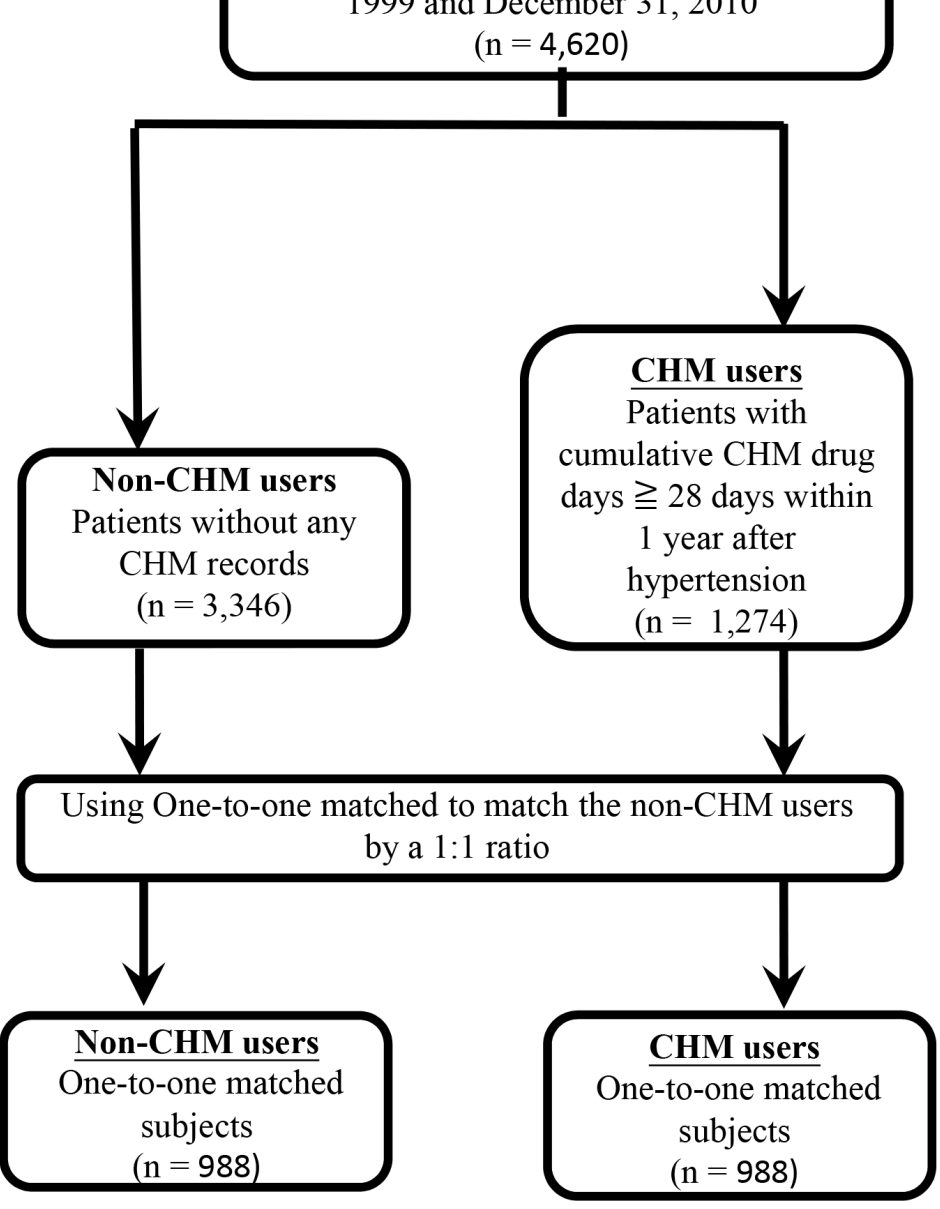

Figure 1: Enrolment of IHD patients with type 2 diabetes.

Abbreviation: CHM, Chinese herbal medicine; IHD, ischemic heart disease. 
Table 1: Characteristics of all subjects and frequency-matched subjects with T2D-related IHD according to CHM use

\begin{tabular}{|c|c|c|c|c|c|c|}
\hline \multirow{4}{*}{ Characteristics } & \multicolumn{3}{|c|}{ Total subjects } & \multicolumn{3}{|c|}{ Matched subjects } \\
\hline & CHM group & non-CHM group & & CHM group & non-CHM group & \\
\hline & $\mathrm{N}=1,274$ & $\mathrm{~N}=3,346$ & $P$-value & $\mathrm{N}=\mathbf{9 8 8}$ & $\mathrm{N}=\mathbf{9 8 8}$ & $P$-value \\
\hline & $\mathbf{N}(\%)$ & $\mathbf{N}(\%)$ & & $\mathbf{N}(\%)$ & $\mathbf{N}(\%)$ & \\
\hline Age, years & & & $<.001$ & & & 1 \\
\hline$<60$ & $485(38.07 \%)$ & $914(27.32 \%)$ & & $333(33.70 \%)$ & $333(33.70 \%)$ & \\
\hline$\geq 60$ & $789(61.93 \%)$ & $2432(72.68 \%)$ & & $655(66.30 \%)$ & $655(66.30 \%)$ & \\
\hline Gender & & & $<.001$ & & & 1 \\
\hline Male & $577(45.29 \%)$ & $2120(63.36 \%)$ & & $497(50.30 \%)$ & $497(50.30 \%)$ & \\
\hline Female & $697(54.71 \%)$ & $1226(36.64 \%)$ & & $491(49.70 \%)$ & $491(49.70 \%)$ & \\
\hline $\begin{array}{l}\text { Duration from T2D to } \\
\text { IHD }\end{array}$ & & & $<.001$ & & & .962 \\
\hline $1-3$ years & $391(30.69 \%)$ & $1229(36.73 \%)$ & & $329(33.30 \%)$ & $328(33.20 \%)$ & \\
\hline$\geq 3$ years & $883(69.31 \%)$ & $2117(63.27 \%)$ & & $659(66.70 \%)$ & $660(66.80 \%)$ & \\
\hline \multirow[t]{3}{*}{$\begin{array}{l}\text { Insulin usage } \\
\text { (index-365 to index) }\end{array}$} & & & & & & 1 \\
\hline & & & & $957(96.86 \%)$ & $957(96.86 \%)$ & \\
\hline & & & & $31(3.14 \%)$ & $31(3.14 \%)$ & \\
\hline COPD & & & $<.001$ & & & $<.001$ \\
\hline No & $804(63.11 \%)$ & $2397(71.64 \%)$ & & $636(64.37 \%)$ & $767(77.63 \%)$ & \\
\hline Yes & $470(36.89 \%)$ & $949(28.36 \%)$ & & $352(35.63 \%)$ & $221(22.37 \%)$ & \\
\hline Hepatitis & & & $<.001$ & & & .003 \\
\hline No & $1169(91.76 \%)$ & $3204(95.76 \%)$ & & $904(91.50 \%)$ & $937(94.84 \%)$ & \\
\hline Yes & $105(8.24 \%)$ & $142(4.24 \%)$ & & $84(8.50 \%)$ & $51(5.16 \%)$ & \\
\hline Ulcer disease & & & $<.001$ & & & $<.001$ \\
\hline No & $692(54.32 \%)$ & $2333(69.73 \%)$ & & $547(55.36 \%)$ & $688(69.64 \%)$ & \\
\hline Yes & $582(45.68 \%)$ & $1013(30.27 \%)$ & & $441(44.64 \%)$ & $300(30.36 \%)$ & \\
\hline $\begin{array}{l}\text { Chronic kidney } \\
\text { disease }\end{array}$ & & & .174 & & & .437 \\
\hline No & $1150(90.27 \%)$ & $2974(88.88 \%)$ & & $892(90.28 \%)$ & $902(91.3 \%)$ & \\
\hline Yes & $124(9.73 \%)$ & $372(11.12 \%)$ & & $96(9.72 \%)$ & $86(8.70 \%)$ & \\
\hline Hyperlipidemia & & & $<.001$ & & & $<.001$ \\
\hline No & $462(36.26 \%)$ & $1730(51.70 \%)$ & & $368(37.25 \%)$ & $445(45.04 \%)$ & \\
\hline Yes & $812(63.74 \%)$ & $1616(48.30 \%)$ & & $620(62.75 \%)$ & $543(54.96 \%)$ & \\
\hline Obesity & & & .025 & & & .316 \\
\hline No & $1264(99.22 \%)$ & $3336(99.7 \%)$ & & $982(99.39 \%)$ & $985(99.7 \%)$ & \\
\hline Yes & $10(0.78 \%)$ & $10(0.30 \%)$ & & $6(0.61 \%)$ & $3(0.30 \%)$ & \\
\hline
\end{tabular}




\begin{tabular}{|c|c|c|c|c|c|c|}
\hline \multirow{4}{*}{ Characteristics } & \multicolumn{3}{|c|}{ Total subjects } & \multicolumn{3}{|c|}{ Matched subjects } \\
\hline & CHM group & non-CHM group & \multirow{3}{*}{$P$-value } & CHM group & non-CHM group & \multirow{3}{*}{$P$ - value } \\
\hline & $\mathrm{N}=1,274$ & $\mathrm{~N}=3,346$ & & $\mathrm{~N}=988$ & $\mathrm{~N}=988$ & \\
\hline & $\mathbf{N}(\%)$ & $\mathbf{N}(\%)$ & & $\mathbf{N}(\%)$ & N (\%) & \\
\hline Alcohol-related illness & & & .607 & & & 1 \\
\hline No & $1268(99.53 \%)$ & $3326(99.4 \%)$ & & $982(99.39 \%)$ & $982(99.39 \%)$ & \\
\hline Yes & $6(0.47 \%)$ & $20(0.60 \%)$ & & $6(0.61 \%)$ & $6(0.61 \%)$ & \\
\hline Tobacco use & & & .588 & & & .795 \\
\hline No & $1265(99.29 \%)$ & $3327(99.43 \%)$ & & $981(99.29 \%)$ & $980(99.19 \%)$ & \\
\hline Yes & $9(0.71 \%)$ & $19(0.57 \%)$ & & $7(0.71 \%)$ & $8(0.81 \%)$ & \\
\hline Income & & & $<.001$ & & & .276 \\
\hline$<\mathrm{NT} 20000$ & $552(43.33 \%)$ & $1708(51.05 \%)$ & & $439(44.43 \%)$ & $464(46.96 \%)$ & \\
\hline NT20000-NT30000 & $421(33.05 \%)$ & $1057(31.59 \%)$ & & $323(32.69 \%)$ & $329(33.3 \%)$ & \\
\hline NT30000-NT40000 & $199(15.62 \%)$ & $323(9.65 \%)$ & & $142(14.37 \%)$ & $114(11.54 \%)$ & \\
\hline$\geq$ NT40000 & $102(8.01 \%)$ & $258(7.71 \%)$ & & $84(8.50 \%)$ & $81(8.20 \%)$ & \\
\hline Urbanization level & & & .02 & & & .877 \\
\hline 1 & $497(39.01 \%)$ & $1292(38.61 \%)$ & & $383(38.77 \%)$ & $393(39.78 \%)$ & \\
\hline 2 & $363(28.49 \%)$ & $816(24.39 \%)$ & & $279(28.24 \%)$ & $270(27.33 \%)$ & \\
\hline 3 & $104(8.16 \%)$ & $293(8.76 \%)$ & & $78(7.89 \%)$ & $88(8.91 \%)$ & \\
\hline 4 & $122(9.58 \%)$ & $371(11.09 \%)$ & & $93(9.41 \%)$ & $86(8.70 \%)$ & \\
\hline 5 & $188(14.76 \%)$ & $574(17.15 \%)$ & & $155(15.69 \%)$ & $151(15.28 \%)$ & \\
\hline
\end{tabular}

Abbreviations: COPD, chronic obstructive pulmonary disease; CHM, Chinese herbal medicine; IHD, ischemic heart disease; T2D, type 2 diabetes.

The comorbidities are diagnosed before the diagnosis of IHD. These include chronic obstructive pulmonary disease (COPD; ICD-9-CM 490-496), hepatitis (ICD-9-CM 070), peptic ulcer disease (ICD-9-CM 531-534), chronic kidney disease (ICD-9-CM 582, 583-583.7, 585, 586, and 588), hyperlipidemia (ICD-9-CM 272), obesity (ICD-9-CM 278 and 278.01), alcoholism (ICD-9-CM 303, 305, 305.01, 305.02, 305.03, and V11.3), and tobacco use (ICD-9-CM 305.1).

and women (HR $0.36,95 \%$ CI $0.20-0.63$ ), regardless of whether the time interval between diagnosis of diabetes and that of IHD was $1-3$ years (HR $0.29,95 \%$ CI 0.14 0.59 ) or more than 3 years (HR $0.56,95 \%$ CI $0.37-0.83$ ).

\section{Top CHM products}

The 12 most commonly used Chinese herbal formulas and single herbs prescribed for the CHM users are listed in Table 2. The composition of these herbal formulas and single herbs is shown in Supplementary Table 1. Shu-Jing-Huo-Xue-Tang (40.7\%) was the most commonly prescribed herbal formula, followed by ShaoYao-Gan-Cao-Tang (34.2\%) and Xue-Fu-Zhu-Yu-Tang (33.6\%). Of the 12 most common single herbs, Yan-HuSuo $(42.4 \%)$ was the most commonly prescribed, followed by Dan-Shen (40.6\%) and Ge-Gen (35.1\%). When subjects were stratified according to use of these herbs, there was a significant protective effect against death $(P<$ .05 ), except for Xuan-Shen (Figure 4).

CHM combination (coprescription) patterns were also investigated (Table 3). The most commonly prescribed combination of herbal formulas or single herbs was Shu-Jing-Huo-Xue-Tang and Shao-Yao-GanCao-Tang (13.6\%) according to percentage of usage. The second most commonly prescribed combination was ShuJing-Huo-Xue-Tang and Du-Huo-Ji-Sheng-Tang (12.3\%), followed by Shao-Yao-Gan-Cao-Tang and Yan-Hu-Suo (11.3\%). Mortality was also investigated for the dual CHM combinations, and significant differences in protective effect were found for the combinations of Shu-Jing-HuoXue-Tang and Shao-Yao-Gan-Cao-Tang (HR 0.23, 95\% CI $0.09-0.61, P=.0032$ ), Niu-Xi and Du-Zhong (HR $0.24,95 \%$ CI $0.08-0.72, P=.0111$ ), Shu-Jing-Huo-XueTang and Du-Huo-Ji-Sheng-Tang (HR 0.25, 95\% CI 0.11- 
A

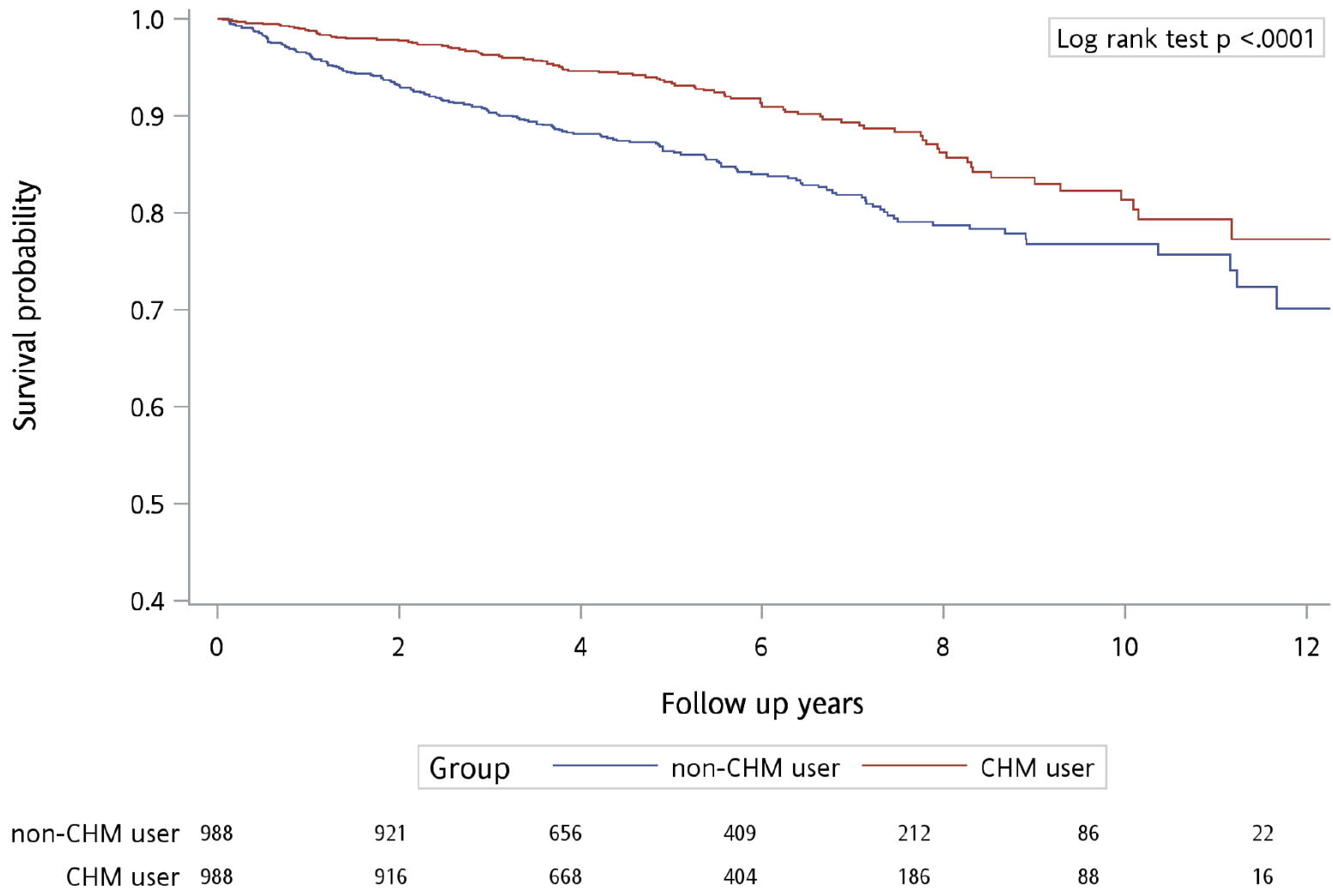

B Left: age $<60$ years

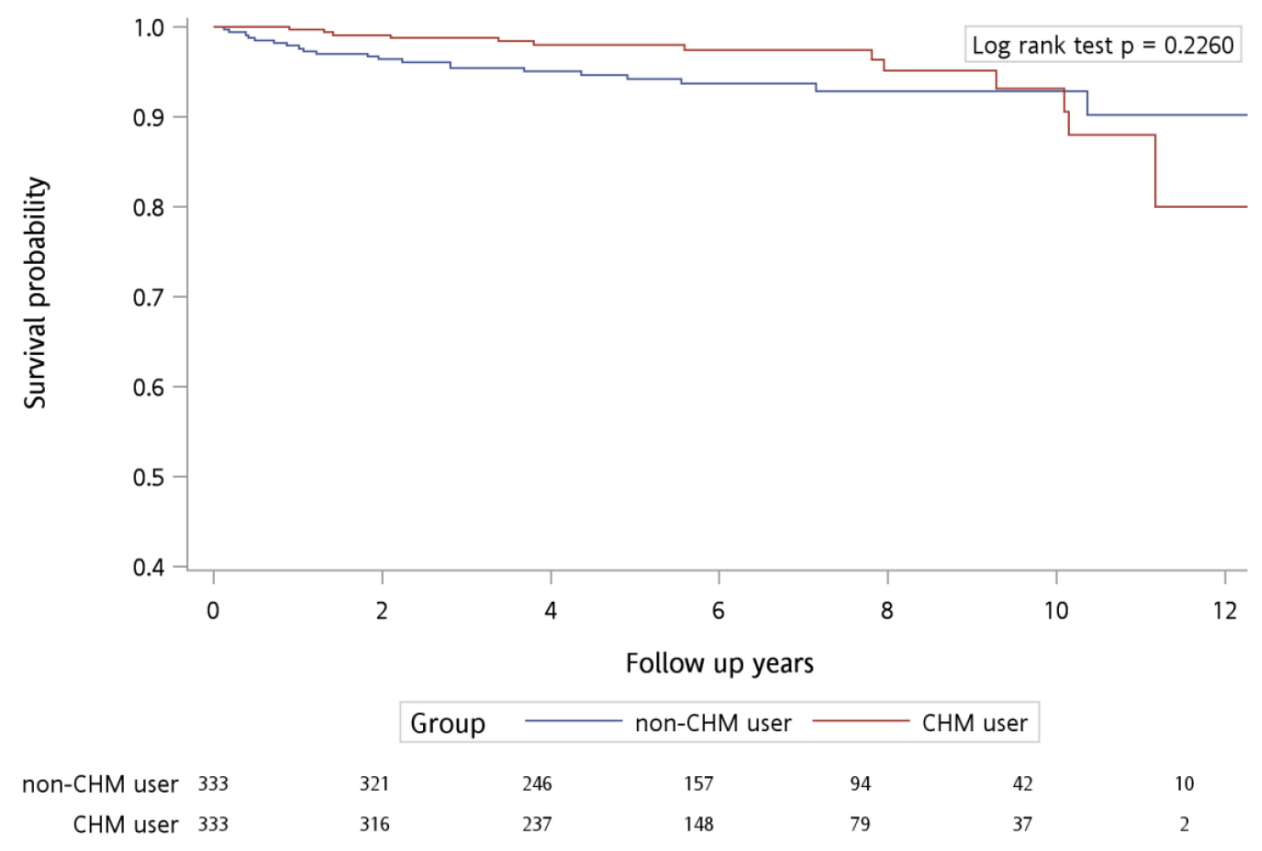

Figure 2: Cumulative probability of survival of IHD patients with type 2 diabetes according to use of CHM in each study group for A. total subject population, B. people younger than 60 years,

(Continued) 


\section{C right: age $\geq 60$ years}

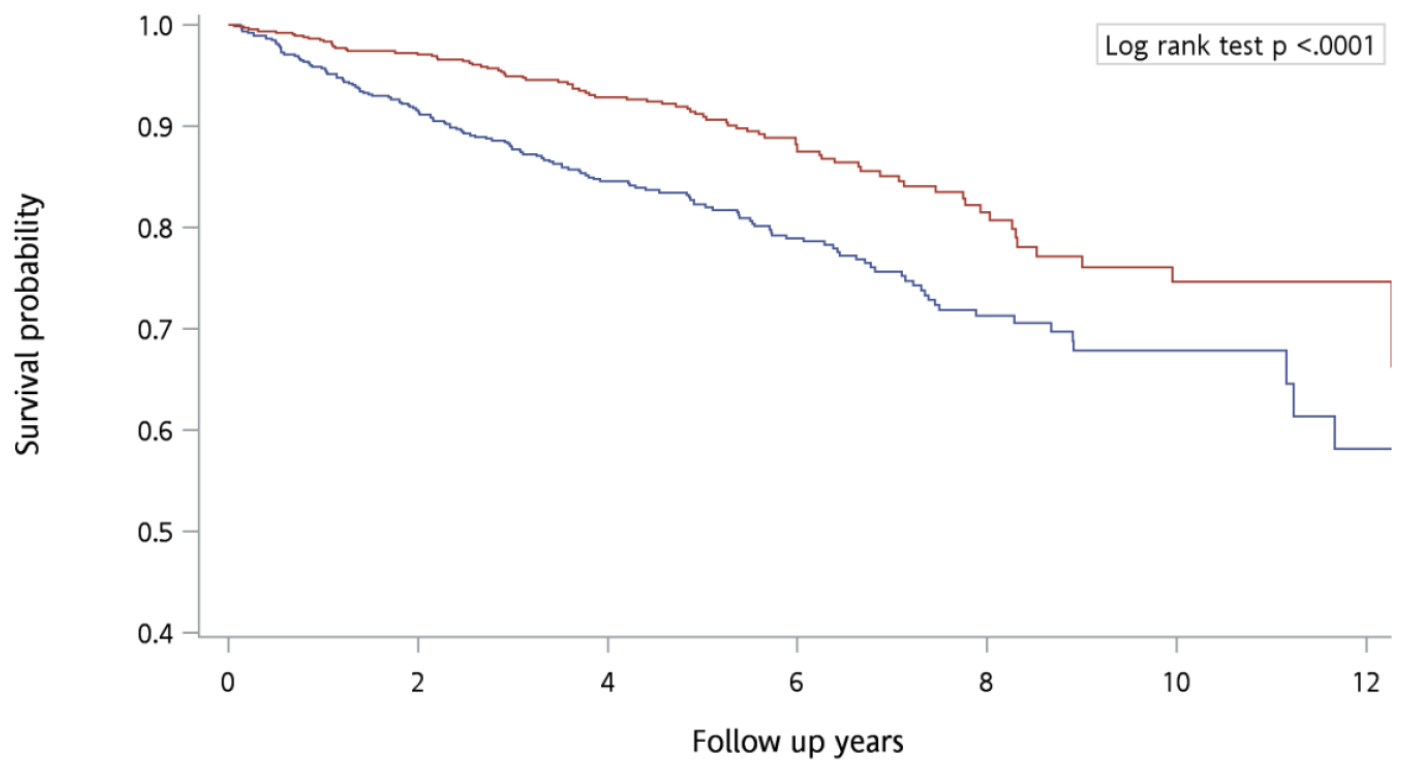

\begin{tabular}{|c|c|c|c|c|c|c|c|}
\hline \multirow[b]{2}{*}{ non-CHM user } & \multirow[b]{2}{*}{600} & Group & & $\mathrm{n}-\mathrm{CH}$ & 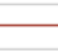 & ser & \\
\hline & & & 410 & 252 & 118 & 44 & 12 \\
\hline CHM user 655 & 600 & & 431 & 256 & 107 & 51 & 14 \\
\hline
\end{tabular}

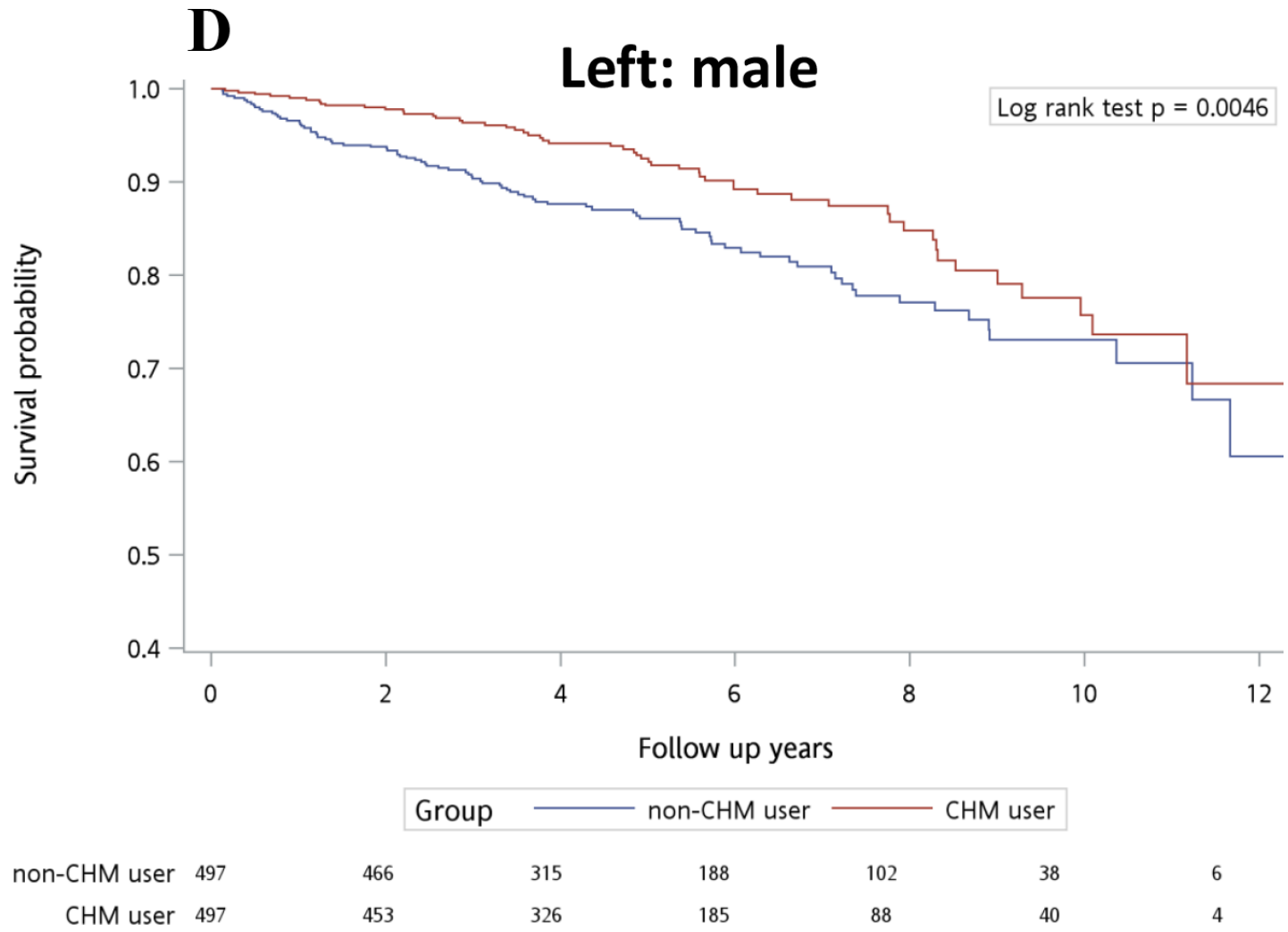

Figure 2 (Continued): C. people aged 60 years or older, and D. male patients and 


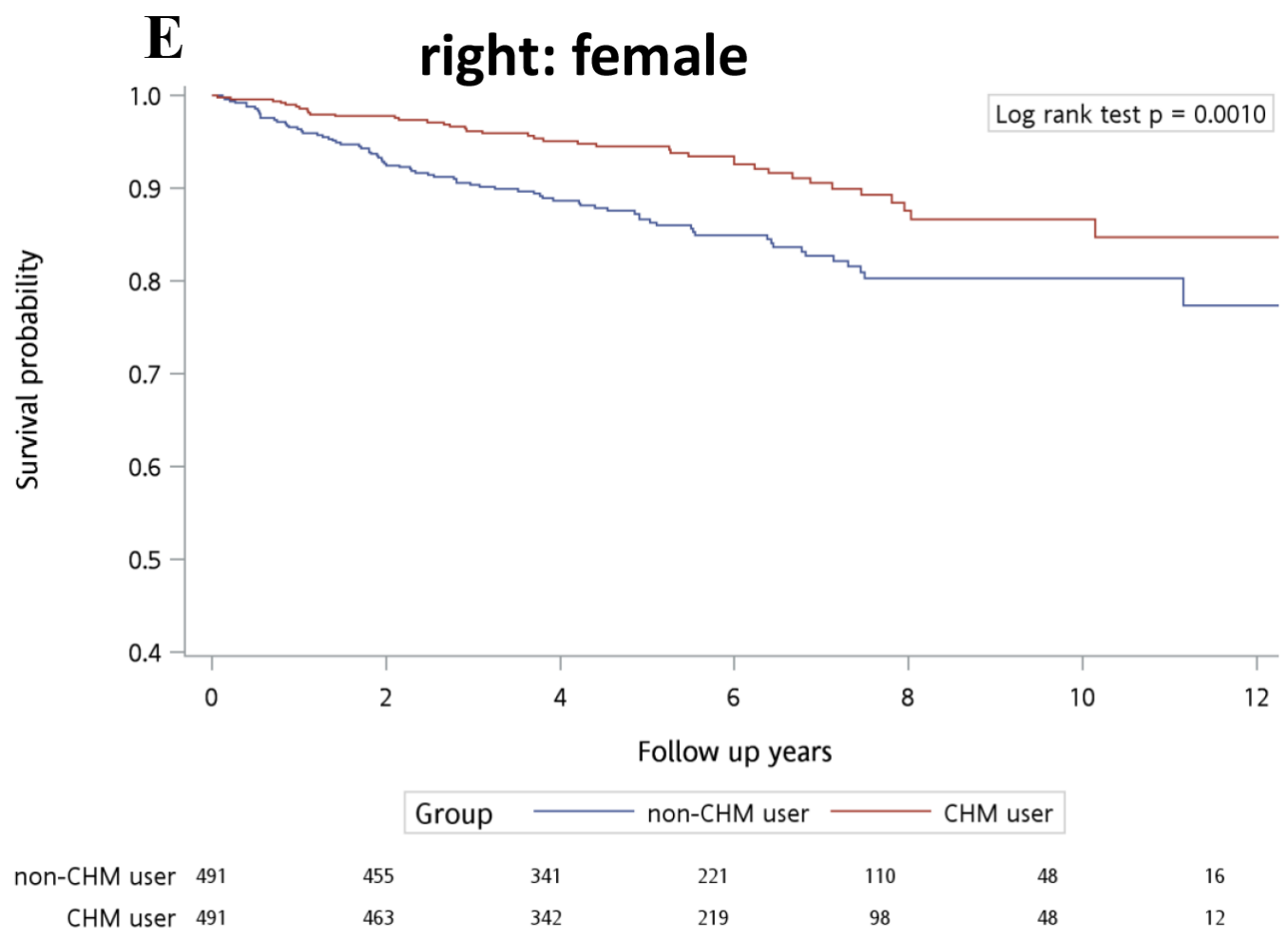

Figure 2 (Continued): E. female patients.

Abbreviation: CHM, Chinese herbal medicine.

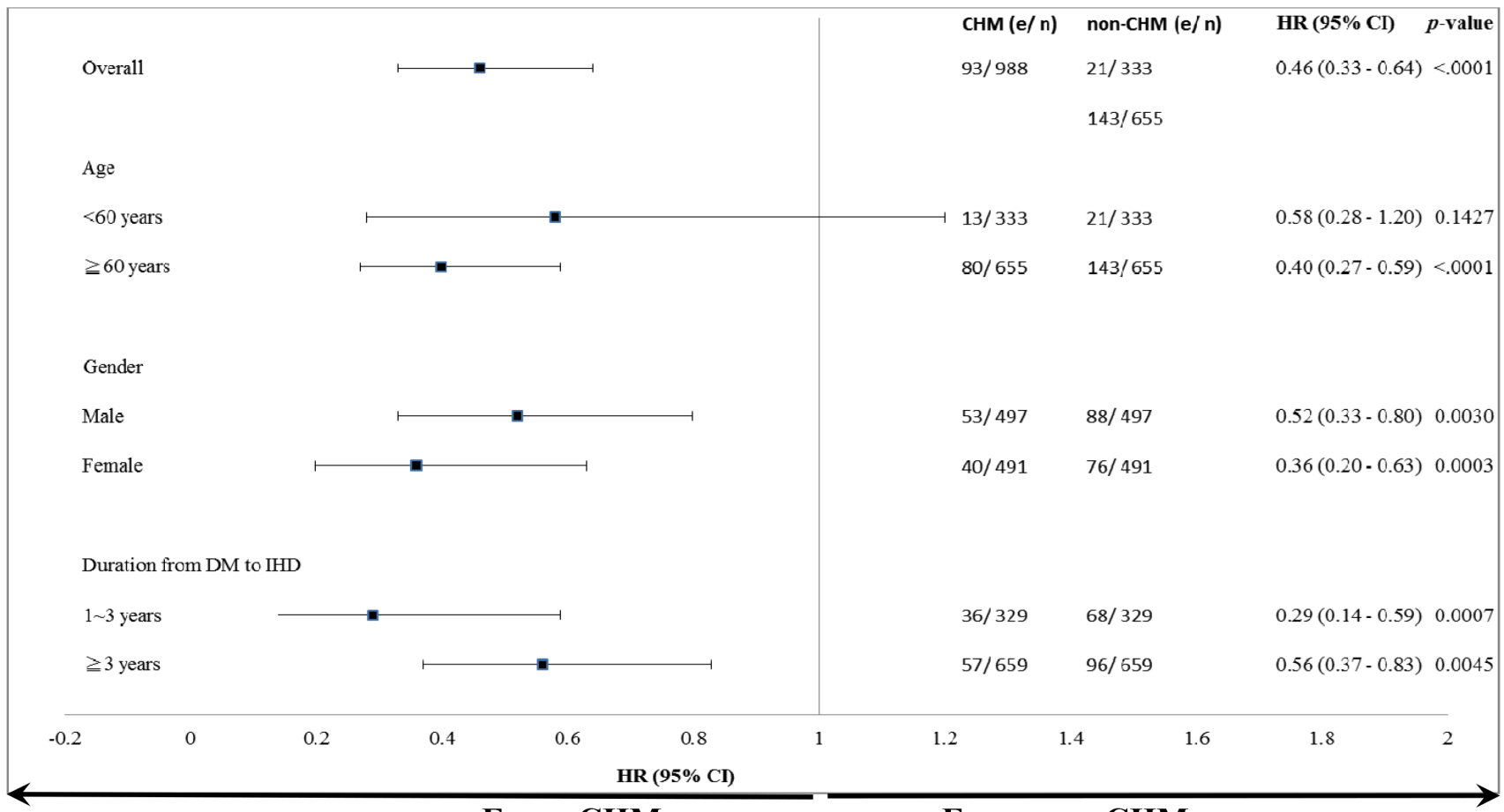

Favor CHM

Favor non-CHM

Figure 3: Subgroup analysis for the endpoint of mortality. Use of CHM was associated with a protective effect when subjects were stratified by age, gender, and duration from diagnosis of DM to diagnosis of IHD.

Abbreviations: CHM, Chinese herbal medicine; DM, diabetes mellitus; IHD, ischemic heart disease. 
Table 2: Twelve most commonly used herbal formulas and single herbs for ischemic heart disease patients with type 2 diabetes

\begin{tabular}{|c|c|c|c|c|c|c|c|c|c|}
\hline Formulas & $\begin{array}{l}\text { Frequency } \\
\text { of user }\end{array}$ & $\begin{array}{c}\text { Person- } \\
\text { year }\end{array}$ & $\begin{array}{l}\text { Frequency of } \\
\text { prescriptions }\end{array}$ & $\begin{array}{c}\text { Percentage } \\
\text { of usage }\end{array}$ & $\begin{array}{l}\text { Total drug } \\
\text { dose per } \\
\text { person- } \\
\text { years (g) }\end{array}$ & $\begin{array}{l}\text { Avg. drug } \\
\text { days per } \\
\text { person }\end{array}$ & $\begin{array}{l}\text { Avg. drug } \\
\text { dose per } \\
\text { person } \\
\text { (g) }\end{array}$ & $\begin{array}{c}\text { Avg. } \\
\text { drug } \\
\text { dose per } \\
\text { day (g) }\end{array}$ & $\begin{array}{c}\text { Average } \\
\text { duration for } \\
\text { prescription } \\
\text { (days) }\end{array}$ \\
\hline Total & 988 & 5523 & 40288 & 100 & 723.1 & 310.8 & 4042.1 & 13 & 7.6 \\
\hline Herbal formula & 985 & 5516 & 38646 & 99.7 & 534.6 & 298 & 2994.1 & 10 & 7.6 \\
\hline $\begin{array}{l}\text { Shu-Jing-Huo- } \\
\text { Xue-Tang }\end{array}$ & 402 & 2401 & 2705 & 40.7 & 33.6 & 46.3 & 200.7 & 4.3 & 6.9 \\
\hline $\begin{array}{l}\text { Shao-Yao-Gan- } \\
\text { Cao-Tang }\end{array}$ & 338 & 2032 & 1642 & 34.2 & 19.9 & 35.8 & 119.6 & 3.3 & 7.4 \\
\hline $\begin{array}{l}\text { Xue-Fu-Zhu- } \\
\text { Yu-Tang }\end{array}$ & 332 & 1975 & 1825 & 33.6 & 32 & 50.5 & 190.3 & 3.8 & 9.2 \\
\hline Ge-Gen-Tang & 320 & 1911 & 1427 & 32.4 & 22.5 & 30.2 & 134.6 & 4.5 & 6.8 \\
\hline $\begin{array}{l}\text { Jia-Wei-Xiao- } \\
\text { Yao-San }\end{array}$ & 318 & 1877 & 1804 & 32.2 & 30.6 & 50.3 & 180.6 & 3.6 & 8.9 \\
\hline $\begin{array}{l}\text { Liu-Wei-Di- } \\
\text { Huang-Wan }\end{array}$ & 309 & 1935 & 1931 & 31.3 & 43.7 & 60 & 273.6 & 4.6 & 9.6 \\
\hline $\begin{array}{l}\text { Zhi-Gan-Cao- } \\
\text { Tang }\end{array}$ & 304 & 1873 & 1899 & 30.8 & 35.5 & 50.4 & 218.6 & 4.3 & 8.1 \\
\hline $\begin{array}{l}\text { Ji-Sheng-Shen- } \\
\text { Qi-Wan }\end{array}$ & 292 & 1743 & 2003 & 29.6 & 42.4 & 63.5 & 252.8 & 4 & 9.3 \\
\hline $\begin{array}{l}\text { Du-Huo-Ji- } \\
\text { Sheng-Tang }\end{array}$ & 287 & 1725 & 1715 & 29 & 37.4 & 49.7 & 224.7 & 4.5 & 8.3 \\
\hline $\begin{array}{l}\text { Xiao-Chai-Hu- } \\
\text { Tang }\end{array}$ & 273 & 1648 & 1138 & 27.6 & 20 & 29.6 & 120.6 & 4.1 & 7.1 \\
\hline Gan-Lu-Yin & 271 & 1599 & 1292 & 27.4 & 24.4 & 36.9 & 144.1 & 3.9 & 7.7 \\
\hline $\begin{array}{l}\text { Ma-Xing-Shi- } \\
\text { Gan-Tang }\end{array}$ & 271 & 1666 & 1171 & 27.4 & 20.4 & 28.6 & 125.5 & 4.4 & 6.6 \\
\hline Single herbs & 963 & 5393 & 31132 & 97.5 & 193.7 & 254.6 & 1084.4 & 4.3 & 7.9 \\
\hline Yan-Hu-Suo & 419 & 2445 & 2259 & 42.4 & 8 & 40.5 & 46.7 & 1.2 & 7.5 \\
\hline Dan-Shen & 401 & 2283 & 2860 & 40.6 & 15.5 & 72.3 & 88.1 & 1.2 & 10.1 \\
\hline Ge-Gen & 347 & 2087 & 1941 & 35.1 & 9.5 & 48.2 & 56.9 & 1.2 & 8.6 \\
\hline Bei-Mu & 321 & 1907 & 1863 & 32.5 & 7.1 & 39.4 & 42.2 & 1.1 & 6.8 \\
\hline Jie-Geng & 307 & 1839 & 1422 & 31.1 & 5.5 & 30.5 & 33 & 1.1 & 6.6 \\
\hline Niu-Xi & 304 & 1848 & 1769 & 30.8 & 8.2 & 46.1 & 49.7 & 1.1 & 7.9 \\
\hline Huang-Qin & 302 & 1813 & 1448 & 30.6 & 8 & 40.5 & 47.9 & 1.2 & 8.5 \\
\hline Huang-Qi & 296 & 1738 & 1490 & 30 & 11.2 & 43 & 65.6 & 1.5 & 8.5 \\
\hline Tian-Hua-Fen & 294 & 1779 & 1558 & 29.8 & 8.6 & 44.7 & 52.3 & 1.2 & 8.4 \\
\hline Mai-Men-Dong & 291 & 1779 & 1240 & 29.5 & 6.2 & 33.7 & 37.7 & 1.1 & 7.9 \\
\hline Xuan-Shen & 267 & 1619 & 1308 & 27 & 8.5 & 42.6 & 51.3 & 1.2 & 8.7 \\
\hline Du-Zhong & 262 & 1575 & 1468 & 26.5 & 10 & 51.3 & 60.3 & 1.2 & 9.2 \\
\hline
\end{tabular}

*Sorted by percentage of usage. 
$0.54, P=.0005)$, and Xue-Fu-Zhu-Yu-Tang and Dan-Shen (HR 0.29, 95\% CI 0.10-0.90, $P=.0313$; Figure 5).

\section{Effect of most commonly prescribed double CHM combinations on $\mathrm{H}_{2} \mathrm{O}_{2}$-induced dephosphorylation of GSK-3 $\beta$ and p38 MAPK in H9C2 cells}

Studies have shown that the apoptosis of myocardial cells is involved in the development of cardiovascular diseases, including IHD, where oxidative stress/injury plays an important role [28], [29]. Therefore, the apoptosis of myocardial cells is an important focus of research into the control and prevention of cardiovascular disease. Apoptosis induced by oxidative stress in $\mathrm{H} 9 \mathrm{C} 2$ cells has been associated with the phosphorylation states of GSK$3 ß$ and MAPKs, such as p38 MAPK [30], [31], [32]. Therefore, to explore the potential signaling pathways contributing to the protective cardiovascular effect of dual CHM combinations, we examined the activation of GSK-3ß and p38 MAPK. We chose the most commonly used dual CHM combinations, i.e., Shu-Jing-Huo-XueTang and Shao-Yao-Gan-Cao-Tang (herbal formula + herbal formula) and Bei-Mu and Jie-Geng (single herb + single herb) according to their percentage use per person. $\mathrm{H} 9 \mathrm{C} 2$ cells were treated with these herbs at the indicated concentrations (Figure 6A) $\mathrm{H}_{2} \mathrm{O}_{2}$ and insulin were used as the negative and positive controls, respectively. The insulin-treated and CHM combination-treated cells were then incubated with a $\mathrm{H}_{2} \mathrm{O}_{2}$ solution. As shown in Figure $6 \mathrm{~A}$, treatment with $\mathrm{H}_{2} \mathrm{O}_{2}$ decreased the phosphorylation of GSK-3ß and p38 MAPK when compared with the cells only. Treatment with $\mathrm{H}_{2} \mathrm{O}_{2}$ decreased the phosphorylation of GSK-3ß to $34.7 \%$ (Figure 6B), which was recovered by insulin (55.3\%), Shu-Jing-Huo-Xue-Tang and Shao-Yao-

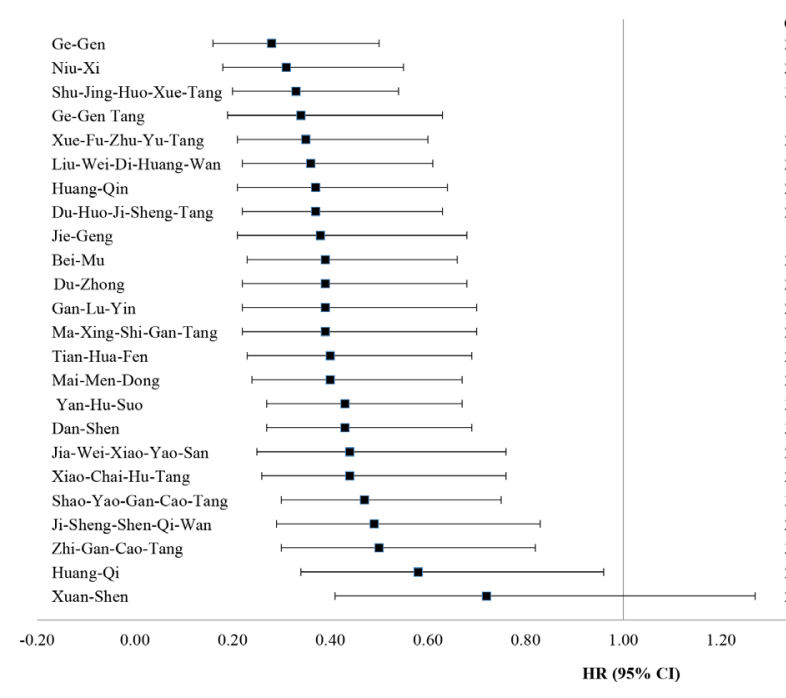

Gan-Cao-Tang $(59.7 \%, p<0.0001)$, and Bei-Mu and JieGeng $(43.0 \%, p=0.0002)$. Treatment with $\mathrm{H}_{2} \mathrm{O}_{2}$ decreased the phosphorylation of p38 MAPK to 41.9\% (Figure 6C), which was only recovered by Shu-Jing-Huo-Xue-Tang and Shao-Yao-Gan-Cao-Tang (51.1\%, $p=0.0014)$.

\section{DISCUSSION}

This population-based study shows that treatment with the most commonly used dual CHM combinations has additive benefits in improving survival in patients diagnosed with IHD after a diagnosis of T2D and on regular insulin therapy. The cumulative probability of survival was higher in CHM users than in non-CHM users. The most commonly used herbal formulas, single herbs, and double CHM combinations were identified and evaluated for their ability to protect against apoptosis induced by oxidative stress in $\mathrm{H} 9 \mathrm{C} 2$ (myocardial) cells. We found that Shu-Jing-Huo-Xue-Tang, Shao-Yao-GanCao-Tang, and their combination had protective effects against $\mathrm{H}_{2} \mathrm{O}_{2}$-induced $\mathrm{H} 9 \mathrm{C} 2$ apoptosis and were able to rescue the decreased phosphorylation of both GSK-3ß and p38 MAPK. This suggests that these commonly used herbs may have a role in antiapoptotic activity in $\mathrm{H} 9 \mathrm{C} 2$ cells exposed to $\mathrm{H}_{2} \mathrm{O}_{2}$ and may be beneficial for cell survival. Our results suggest that adjunctive CHM combination therapy may improve the overall survival rate of IHD patients with T2D by increasing the survival of myocardial cells.

Our study revealed a higher probability of overall survival in IHD patients with T2D who were users of CHM. Our study also revealed that mortality rates in $\mathrm{CHM}$ users were not inferior to those in non-CHM users (Supplementary Table 2). Several clinical studies also support our observations. A combination of CHM

Figure 4: Effect of herbal formulas and single herbs most commonly used to reduce the mortality risk for IHD patients with type 2 diabetes.

Abbreviations: CHM, Chinese herbal medicine; CI, confidence interval; HR, hazard ratio; IHD, ischemic heart disease. 
Table 3: Twelve most commonly used Chinese herbal medicine combinations for ischemic heart disease patients with type 2 diabetes

\begin{tabular}{|c|c|c|c|c|c|c|c|c|c|}
\hline CHM combinations & $\begin{array}{l}\text { Frequency } \\
\text { of user }\end{array}$ & $\begin{array}{c}\text { Person- } \\
\text { year }\end{array}$ & $\begin{array}{l}\text { Frequency of } \\
\text { prescriptions }\end{array}$ & $\begin{array}{l}\text { Percentage } \\
\text { of usage }\end{array}$ & $\begin{array}{l}\text { Total drug } \\
\text { dose per } \\
\text { person- } \\
\text { years }(\mathrm{g})\end{array}$ & $\begin{array}{c}\text { Avg. drug } \\
\text { days per } \\
\text { person }\end{array}$ & $\begin{array}{l}\text { Avg. drug } \\
\text { dose per } \\
\text { person (g) }\end{array}$ & $\begin{array}{l}\text { Avg. drug } \\
\text { dose per } \\
\text { day (g) }\end{array}$ & $\begin{array}{c}\text { Average } \\
\text { duration for } \\
\text { prescription } \\
\text { (days) }\end{array}$ \\
\hline TOTAL & 843 & 4823 & 10195 & 100 & 101.7 & 101.8 & 581.7 & 5.7 & 8.4 \\
\hline $\begin{array}{l}\text { Shu-Jing-Huo-Xue- } \\
\text { Tang and Shao-Yao- } \\
\text { Gan-Cao-Tang }\end{array}$ & 115 & 696 & 407 & 13.6 & 27.6 & 23.2 & 166.9 & 7.2 & 6.5 \\
\hline $\begin{array}{l}\text { Shu-Jing-Huo-Xue- } \\
\text { Tang and Du-Huo- } \\
\text { Ji-Sheng-Tang }\end{array}$ & 104 & 631 & 474 & 12.3 & 47.1 & 33.9 & 285.8 & 8.4 & 7.4 \\
\hline $\begin{array}{l}\text { Shao-Yao-Gan-Cao- } \\
\text { Tang and Yan-Hu- } \\
\text { Suo }\end{array}$ & 95 & 568 & 168 & 11.3 & 9.1 & 11.6 & 54.5 & 4.7 & 6.5 \\
\hline $\begin{array}{l}\text { Shu-Jing-Huo-Xue- } \\
\text { Tang and Yan-Hu- } \\
\text { Suo }\end{array}$ & 93 & 550 & 282 & 11 & 15.7 & 20.8 & 92.7 & 4.5 & 6.8 \\
\hline $\begin{array}{l}\text { Bei-Mu and Jie- } \\
\text { Geng }\end{array}$ & 84 & 502 & 236 & 10 & 6.6 & 18.8 & 39.4 & 2.1 & 6.7 \\
\hline $\begin{array}{l}\text { Zhi-Gan-Cao-Tang } \\
\text { and Dan-Shen }\end{array}$ & 83 & 484 & 269 & 9.8 & 29.2 & 32.1 & 170.2 & 5.3 & 9.9 \\
\hline $\begin{array}{l}\text { Xue-Fu-Zhu-Yu- } \\
\text { Tang and Dan-Shen }\end{array}$ & 77 & 458 & 296 & 9.1 & 35.5 & 45.5 & 211.3 & 4.6 & 11.8 \\
\hline $\begin{array}{l}\text { Niu-Xi and Du- } \\
\text { Zhong }\end{array}$ & 76 & 475 & 308 & 9 & 12.9 & 31.8 & 80.6 & 2.5 & 7.8 \\
\hline $\begin{array}{l}\text { Mai-Men-Dong and } \\
\text { Xuan-Shen }\end{array}$ & 75 & 496 & 221 & 8.9 & 7.6 & 22.8 & 50.4 & 2.2 & 7.7 \\
\hline $\begin{array}{l}\text { Yan-Hu-Suo and } \\
\text { Dan-Shen }\end{array}$ & 73 & 430 & 298 & 8.7 & 13.5 & 38.5 & 79.3 & 2.1 & 9.4 \\
\hline $\begin{array}{l}\text { Du-Huo-Ji-Sheng- } \\
\text { Tang and Yan-Hu- } \\
\text { Suo }\end{array}$ & 70 & 423 & 169 & 8.3 & 17.3 & 19.2 & 104.5 & 5.4 & 8 \\
\hline $\begin{array}{l}\text { Dan-Shen and } \\
\text { Ge-Gen }\end{array}$ & 69 & 402 & 262 & 8.2 & 12.3 & 33.7 & 71.4 & 2.1 & 8.9 \\
\hline
\end{tabular}

*Sorted by percentage of usage.

and conventional medicine might reduce major adverse cardiac events (MACE) in coronary artery disease patients, including all-cause death in hospital and during one-year follow-up, acute myocardial infarction, percutaneous coronary intervention, and coronary artery bypass graft [33]. In addition, adjunctive therapy with Salvia miltiorrhiza (Dan-Shen) and Pueraria lobata (Ge-Gen) in coronary patients led to improvements in vascular function and structure by reducing the levels of low density lipoprotein [34]. Adjunctive therapy with Chinese herbal medicine improves blood perfusion, heart function, and decreases the incidence of MACE in patients with acute coronary syndrome after percutaneous coronary intervention or after revascularization by intravenous thrombolysis or coronary bypass [35][36]. CHM prevents or ameliorates the disease progression from impaired glucose tolerance to diabetes in hyperglycemia patients [37], [38]. Further, CHM may exhibit pharmacological actions including increasing insulin secretion and sensitivity, enhancing the uptake of glucose by adipose and muscle tissues, inhibiting glucose absorption by the intestine, and inhibiting the production of glucose by the liver [10], [11], [39]. These findings may explain the better probability of survival seen in CHM users. We also recorded the regular medications taken by CHM and non-CHM users for the 365 days prior to the index date (Supplementary Table 3). There was no difference in the use of antidiabetic medication between the two groups, except for sulfonylurea agents, which were more prevalent in the non-CHM group. Conversely, more patients in the CHM group used antihypertensive medication. There 
was no difference in the use of antihyperlipidemic agents between the two groups.

A higher probability of survival was still seen in $\mathrm{CHM}$ users when stratified by age and sex. CHM use was also associated with a protective effect against death in patients aged 60 years or older, regardless of sex or the time interval between diagnosis of diabetes and that of IHD. In addition, when mortality risk was stratified according to the herbs used, the most commonly used herbal formulas and single herbs were associated with a protective effect, except for Xuan-Shen. Protective effects against death were also observed in users of double CHM combinations, including Shu-Jing-Huo-Xue-Tang and Shao-Yao-Gan-Cao-Tang, Niu-Xi and Du-Zhong, ShuJing-Huo-Xue-Tang and Du-Huo-Ji-Sheng-Tang, and XueFu-Zhu-Yu-Tang and Dan-Shen. Based on its protective effect against death and high percentage of usage, we chose Shu-Jing-Huo-Xue-Tang, Shao-Yao-Gan-Cao-Tang, and their combination for the functional characterization of their protective effect against $\mathrm{H}_{2} \mathrm{O}_{2}$-induced apoptosis in cardiac cells. The decreased phosphorylation of both GSK-3ß and $\mathrm{p} 38$ MAPK caused by $\mathrm{H}_{2} \mathrm{O}_{2}$ was rescued in herb-treated cells (Supplementary Figure 1). The antiapoptotic activity of Shu-Jing-Huo-Xue-Tang, Shao-YaoGan-Cao-Tang, and their combination against $\mathrm{H}_{2} \mathrm{O}_{2}$ was assessed using the TUNEL assay, which demonstrated their protective effects (Supplementary Figure 2).

Shu-Jing-Huo-Xue-Tang is the herbal formula most commonly prescribed for elderly people in Taiwan [40], and is composed of 17 herbs. Shu-Jing-Huo-Xue-Tang has been prescribed for hundreds of years to treat chronic pain syndromes. It has also been used to treat other conditions, including fractures [41] and prostate cancer, and to reduce the risk of endometrial cancer in women with breast cancer [42]. Shu-Jing-Huo-Xue-Tang has been reported to have analgesic effects in a rat model of adjuvant arthritis [43] and in rats with chronic constriction injury [44]. Among the 17 single herbs in the formulation, Radix Paeoniae Alba (Bai-Shao) and Radix Angelicae Sinensis (Dang-Gui) are the major single herbs. Radix Paeoniae Alba (Bai-Shao) is known to contain at least 11 chemical compounds [45], one of which is paeoniflorin [45][46] [47][48][49]. Paeoniflorin exhibits pharmacological activities including anti-inflammatory [50], anti-oxidant [51], and immunoregulatory activities [52]. Paeoniflorin also had neuroprotective effects in a cerebral ischemia rat model [53]. Furthermore, paeoniflorin attenuated acute myocardial infarction in a rat model [54][55] and protected diabetic mice against myocardial ischemic injury [56]. The two main components of Radix Angelicae Sinensis (Dang-Gui) are ferulic acid and coniferyl ferulate [57] [58]. Ferulic acid lowers blood pressure in spontaneously hypertensive rats [59], induces antioxidant enzyme activity [60], and is cardioprotective in experimental rat models [61][62]. Coniferyl ferulate is an ester of ferulic acid, and has multiple pharmacological activities including antibacterial [63] and antioxidant effects [64].

Shao-Yao-Gan-Cao-Tang is composed of Radix Paeoniae Alba (Bai-Shao) and Radix Glycyrrhizae Preparata. It is the third most common herbal formula prescribed for elderly people in Taiwan [40], and has also been used to treat the acute pain associated with muscle cramps via inhibiting the contraction of skeletal muscles and normalizing intracellular and extracellular potassium

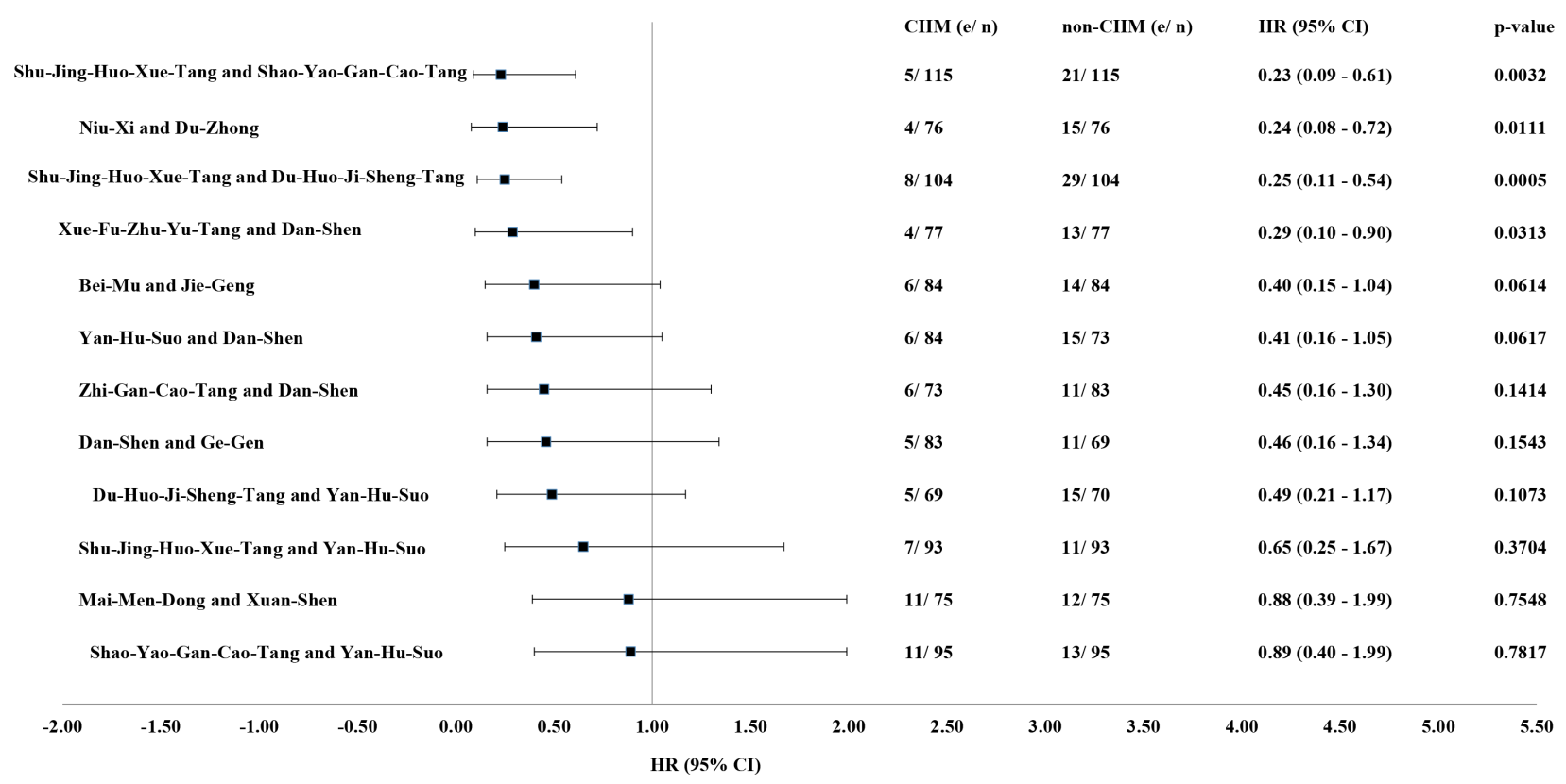

Figure 5: Effect of the double CHM combinations most commonly used to reduce the mortality risk for IHD patients with type 2 diabetes.

Abbreviations: CHM, Chinese herbal medicine; CI, confidence interval; HR, hazard ratio; IHD, ischemic heart disease. 
current balance [65], [66]. The three main components of Shao-Yao-Gan-Cao-Tang are paeoniflorin, glycyrrhizin, and glycyrrhizic acid [46][47][48][49]. Glycyrrhizin enhances cardiac performance in rats [67][68], attenuates Coxsackievirus B3-induced myocarditis [69], and protects the rat heart against ischemia-reperfusion injury [70]. Glycyrrhizic acid also exhibits cardioprotective effects against isoproterenol-induced myocardial ischemia in rats [71] and improves lipoprotein lipase expression, insulin sensitivity, serum lipid, and lipid deposition in high-fat diet-induced obese rats [72].

We therefore examined the effects of these five components (paeoniflorin, glycyrrhizin, glycyrrhizic acid, ferulic acid, and coniferyl ferulate, respectively)

$\mathbf{A}$

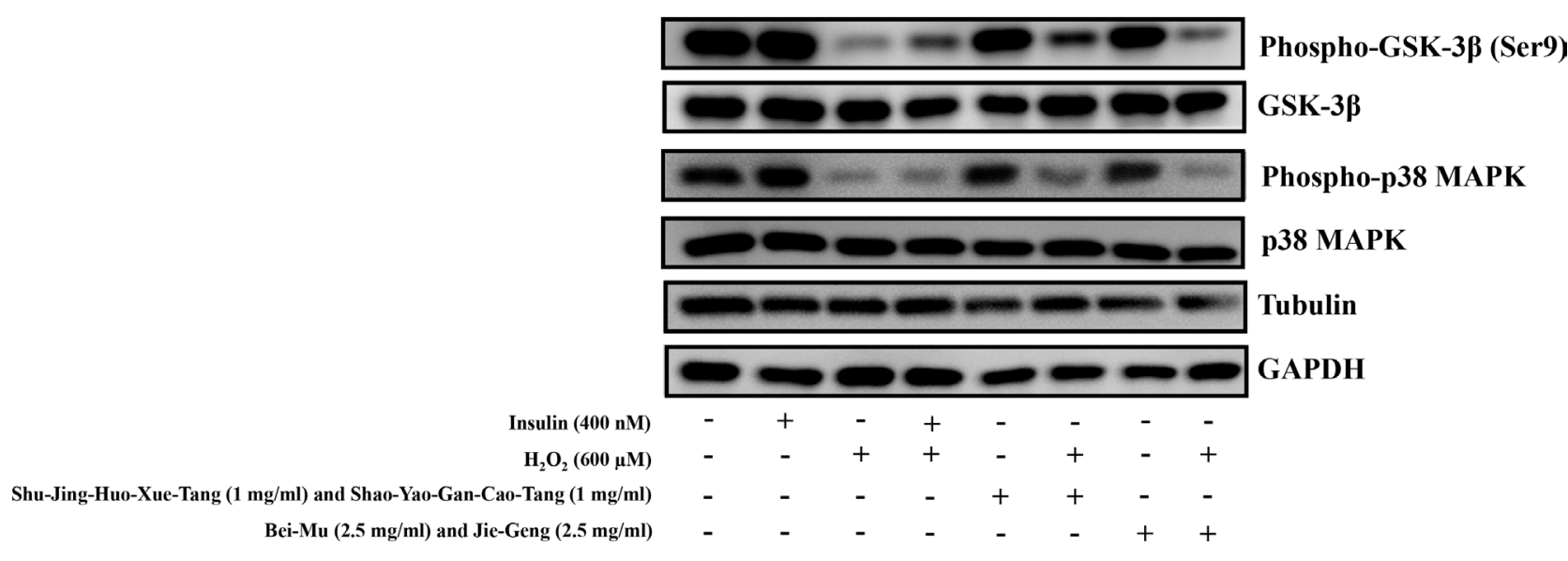

B

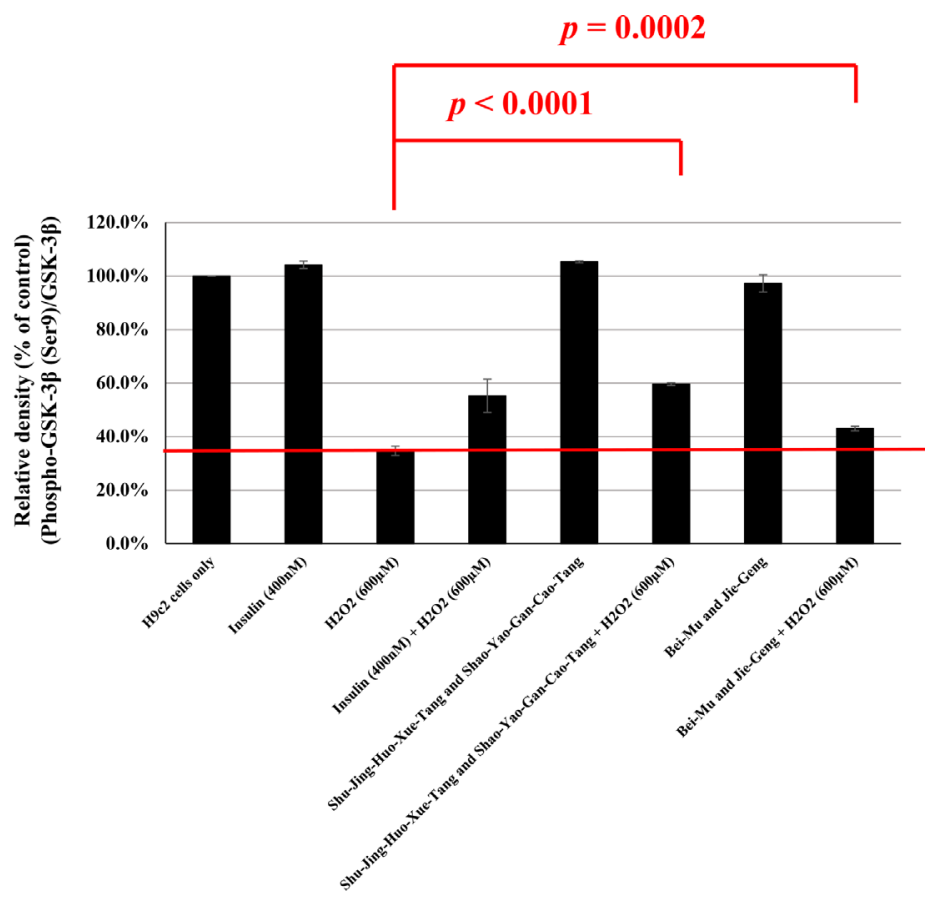

Figure 6: Western blot analysis of the Shu-Jing-Huo-Xue-Tang and Shao-Yao-Gan-Cao-Tang (1 mg/mL each) or BeiMu and Jie-Geng $(2.5 \mathrm{mg} / \mathrm{mL}$ each) in hydrogen peroxide-treated H9C2 cells. A. Western blot analysis of phospho-GSK-3 $\beta$ (Ser9), GSK-3 $\beta$, phospho-p38 MAPK, and p38 MAPK expressions. B. The ratio of phospho-GSK-3 $\beta$ (Ser9) to GSK-3 $\beta$ in various groups $\left[(\text { phospho-GSK-3 } \beta \text { (Ser9)/ GSK-3 } \beta)_{\text {group }} /(\text { phospho-GSK-3 } \beta \text { (Ser9)/ GSK-3 } \beta)_{\text {cells only }} \times 100 \%\right]$.

(Continued) 


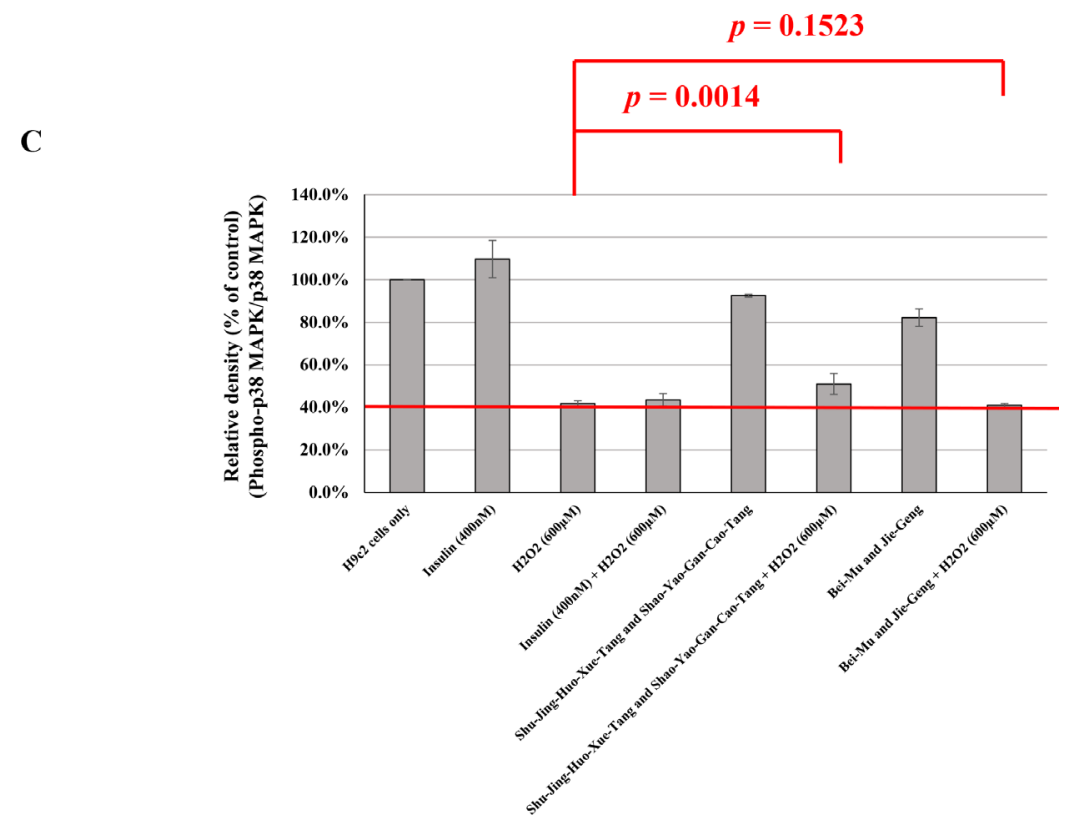

Figure 6 (Continued): C. The ratio of phospho-p38 MAPK to p38 MAPK in various groups [(phospho-p38 MAPK / p38 MAPK) ${ }_{\text {group }}$ (phospho-p38 MAPK / p38 MAPK) cells only $\times 100 \%$ ]. The mean \pm standard error values for at least three independent experiments are shown, along with representative Western blots.

on the phosphorylation of GSK-3ß and p38 MAPK in $\mathrm{H} 9 \mathrm{C} 2$ cells and found that they have variable effects on phosphorylation regulation (Supplementary Figure 3). Among them, we found that paeoniflorin, glycyrrhizic acid, and glycyrrhizin may enhance the GSK-3ß phosphorylation, and paeoniflorin, ferulic acid, and coniferyl ferulate may enhance the p38 MAPK phosphorylation in $\mathrm{H} 9 \mathrm{C} 2$ cells. Although there is no evidence that Shu-Jing-Huo-Xue-Tang and Shao-YaoGan-Cao-Tang have beneficial effects on cardiovascular diseases, either based on their formula or published literature, the components in the two formulas may have reacted with each other when mixed to treat the $\mathrm{H} 9 \mathrm{C} 2$ cells. To our knowledge, this is the first study to show that these CHM combinations may participate in the antiapoptotic activity of $\mathrm{H} 9 \mathrm{C} 2$ cells exposed to $\mathrm{H}_{2} \mathrm{O}_{2}$ via phosphorylation of GSK-3ß and p38 MAPK, and could be beneficial for cell survival.

The results of clinical research using the National Health Insurance Research database in Taiwan combined with our functional characterization of CHM in vitro may provide evidence for the therapeutic efficacy of CHM. The main limitation of this study is the lack of data on blood chemistry in the National Health Insurance Research database in Taiwan. CHM delayed mortality in IHD patients with T2D but did not prevent it. CHM improves overall survival in these patients and enhances the antiapoptotic activity of cardiac cells. Our study provides a comprehensive list of CHM products that may be useful in future investigations of their safety and efficacy in IHD patients with T2D.

\section{MATERIALS AND METHODS}

\section{Data source}

The National Health Insurance Research database (http://nhird.nhri.org.tw/en/index.htm) is available for scientists in Taiwan for research purposes. The data used in this study were retrieved from the "Longitudinal Health Insurance Database (LHID2000 and LHID2005)". This database comprises a random sample of 1 million patients alive from the NHIRD in 2000 (2005), which provides longitudinally linked data for the 1996-2012 period. The NHRI attests that no statistical differences in age, sex and health care costs exist between the LHID2000 (LHID2005) data and those of all enrollees. In the LHID2000 (LHID2005), the original identification number for each patient is encrypted for privacy; however, all data sets can be linked together through unique and anonymous identifiers created by the NHRI. This database contains detailed medical records for each patient, including demographics, diagnoses, prescriptions, records of clinical visits and hospitalizations, inpatient orders, ambulatory care, and sociodemographic factors. Both licensed CHM and Western medicinal practitioners follow a standard diagnosis protocol using the International Classification of Disease, $9^{\text {th }}$ Revision, Clinical Modification (ICD-9-CM).

We included 189,540 individuals with diabetes (ICD-9-CM 250) between 1998 and 2010 (Figure 1). The ICD-9-CM for IHD used in this study was 410-414. Individuals under the age of 20 years were excluded. People whose IHD predated their diabetes, those who had 
IHD diagnosed within one year of being diagnosed to have diabetes, and those who were diagnosed to have IHD after 2009 were also excluded. After all of these criteria were applied, 4620 study subjects were included in the study.

People who had IHD diagnosed one year after being diagnosed as having diabetes were included. People with a cumulative number of CHM treatment days of more than 28 within the first year after being diagnosed to have IHD were defined as CHM users $(n=1,274$, Figure 1). Study subjects with no record of CHM use were defined as non-CHM users $(n=3,346)$. The date on which the criterion of 28 cumulative days of CHM prescription was met was designated as the index date. Demographic data, including age, gender, income and urbanization level, were collected. Urbanization levels in Taiwan are divided into five strata according to the Taiwan National Health Research Institute, with level 1 referring to the most urbanized communities and level 5 referring to the least urbanized communities [73]. We identified the comorbidities that had been diagnosed in CHM users and non-CHM users before their diagnosis of IHD. These were chronic obstructive pulmonary disease (COPD; ICD-9-CM 490-496), hepatitis (ICD-9-CM 070), peptic ulcer disease (ICD-9-CM 531-534), chronic kidney disease (ICD-9CM 582, 583-583.7, 585, 586, and 588), hyperlipidemia (ICD-9-CM 272), obesity (ICD-9-CM 278 and 278.01), alcoholism (ICD-9-CM 303, 305, 305.01, 305.02, 305.03, and V11.3), and tobacco use (ICD-9-CM 305.1).

To reduce bias due to confounding variables, non-CHM users were selected 1:1 after matching for age, gender, and insulin use. In total, 988 subjects were selected for each group (Table 1). The study end was defined as the following: date of death, date of withdrawal from the NHI program, or date of termination of follow-up (31 Dec. 2010). This study was designed as a populationbased retrospective cohort study to explore the effect of treatment with CHM on the overall survival rate of IHD patients with T2D.

\section{Chinese herbal medicine}

All drug codes for CHM (herbal formulas and single herbs) were collected and grouped according to name. For the CHM users, the frequencies of prescriptions, cumulative drug doses (days), average duration per prescription, and person years of follow-up were calculated from index date to the study end. Single herbs were from plant, animal, or mineral sources and could be mixed with other herbs to create a combination product. Herbal formulations usually constituted a combination of more than two herbs (Supplementary Table 1), created by knowledgeable practitioners of traditional Chinese medicine; these formulas have been used for thousands of years in China. The single herbs and herbal formulas were all manufactured by traditional Chinese medicine manufacturers with Good Manufacturing Practice certification and based in Taiwan. These manufacturers are Sun Ten Pharmaceutical Co. Ltd. (http://www.sunten. com.tw/), Chuang Song Zong Pharmaceutical Co. Ltd. (http://www.csz.com.tw/), Shang Chang Pharmaceutical Co. Ltd. (http://www.herb.com.tw/about_en.php), KO DA Pharmaceutical Co. Ltd. (http://www.koda.com.tw/ index_e.aspx), and Kaiser Pharmaceutical Co. Ltd (http:// www.kpc.com/).

\section{Cell culture, reagents, and western blotting}

An H9C2 cell line (myocardial cells derived from Rattus norvegicus) were maintained in Dulbecco's modified Eagle's medium supplemented with 10\% fetal bovine serum, $100 \mathrm{U} / \mathrm{mL}$ penicillin, $100 \mathrm{U} / \mathrm{mL}$ streptomycin, and $2 \mathrm{mM}$ L-glutamine (Gibco, Thermo Fisher Scientific, Waltham, MA, USA). Human insulin solution (catalog number I9278), and hydrogen peroxide $\left(\mathrm{H}_{2} \mathrm{O}_{2}\right)$ solution (catalog number 18304) were purchased from Sigma-Aldrich (St Louis, MO, USA). Control H9C2 cells were treated with insulin $(400 \mathrm{nM})$ for 2 hours and the experimental $\mathrm{H} 9 \mathrm{C} 2$ cells were treated with a CHM combination of Shu-Jing-Huo-Xue-Tang $(1 \mathrm{mg} / \mathrm{mL})$ and Shao-Yao-Gan-Cao-Tang (1 mg/mL) or Bei-Mu $(2.5 \mathrm{mg} /$ $\mathrm{mL}$ ) and Jie-Geng $(2.5 \mathrm{mg} / \mathrm{mL}$ ) for 2 hours (Table 3 ; Figure 6). The insulin-treated cells and CHM combinationtreated cells were then incubated in $\mathrm{H}_{2} \mathrm{O}_{2}$ solution (600 $\mu \mathrm{M})$ for 30 minutes. The cells were then lysed in RIPA buffer (catalog number 89900, Pierce, Thermo Fisher Scientific, Rockford, IL, USA) with a protease inhibitor (complete EDTA-free protease inhibitor, catalog number 11873580001, Roche Life Science, Sigma-Aldrich) and a phosphatase inhibitor (catalog number 88667, Pierce), subjected to $12 \%$ sodium dodecyl sulfate polyacrylamide gel electrophoresis, and then transferred to polyvinylidene fluoride membranes (Millipore, Billerica, MA, USA). The membranes were incubated with primary antibodies overnight at $4{ }^{\circ} \mathrm{C}$. The primary antibodies included antiphospho-p38 MAPK (Thr180/Tyr182; D3F9, catalog number 4511), anti-p38 MAPK (catalog number 9212), anti-phospho-GSK-3 $\beta$ (Ser9, catalog number 9336S), and anti-GSK-3 $\beta$ (catalog number 12456P) from Cell Signaling Technology, Inc. (Beverly, MA, USA), and antitubulin (catalog number 11224-1-AP), and anti-GAPDH (catalog number 10494-1-AP) antibodies from Proteintech Group Inc. (Rosemont, IL, USA). The membranes were then incubated with alkaline phosphatase-conjugated secondary antibodies (Sigma-Aldrich). Signals were visualized using a chemiluminescence kit (Chemicon), following the manufacturer's protocol.

\section{Statistical analysis}

The demographic data in the CHM and non-CHM groups were compared for categorical variables including age, gender, duration from diabetes to IHD, insulin usage 
before index date, comorbidities (chronic obstructive pulmonary disease (COPD), hepatitis, ulcer disease, chronic kidney disease (CKD), hyperlipidemia, obesity, alcoholism, and tobacco use), income, and urbanization level. Chi-squared tests were used to detect any differences (Table 1). The top 12 most common herbal formulas and single herbs used are shown in Table 2. The Kaplan-Meier method was used to estimate cumulative probability of survival (Figure 2). The log-rank test was used to explore the effect of CHM on the overall survival rate of individuals after ischemic heart disease among type 2 diabetes patients (CHM and non-CHM users). Further, the subjects were stratified according to whether they were younger than 60 years (Figure 2B) or 60 years of age or older (Figure 2C) and whether they were male (Figure 2D) or female (Figure 2E). A Cox proportional hazard model adjusting for comorbidities, income, and urbanization level was used to estimate the hazard ratio (HR) of all-cause mortality in subjects after ischemic heart disease among type 2 diabetes patients. All $P$ values less than .05 were considered to be statistically significant. All data management and statistical analyses were performed using SAS software (version 9.4; SAS Institute, Cary, NC, USA).

\section{Abbreviations}

CI: Confidence interval; CHM: Chinese herbal medicine; COPD: Chronic obstructive pulmonary disease; HR: Hazard ratio; IHD: ischemic heart disease; MACE: Major adverse cardiac events; T2D: Type 2 diabetes.

\section{ACKNOWLEDGMENTS}

The authors wish to thank the Division of Chinese Medicine, China Medical University, Beigang Hospital, for administrative assistance and consultation. This study was supported by grants from the China Medical University (CMU102-PH-01 and CMU100-S-01), the China Medical University Hospital (DMR-105-031, DMR-105-098, and DMR-106-155), the National Science Council, the Ministry of Science and Technology, Taiwan (MOST 1032320-B-039 -006 -MY3 and MOST 105-2314-B-039-037MY3), and China Medical University under the Aim for Top University Plan of the Ministry of Education, Taiwan. We also thank Dr. Kuan-Teh Jeang and Willy WL Hong for their technical help and suggestions.

\section{CONFLICTS OF INTEREST}

The authors declare no conflicts of interest.

\section{REFERENCES}

1. Ginter E, Simko V. Type 2 diabetes mellitus, pandemic in 21st century. Adv Exp Med Biol [Internet]. 2013/02/09.
2012; 771: 42-50. Available from http://www.ncbi.nlm.nih. gov/pubmed/23393670.

2. Ma RCW, Chan JCN. Type 2 diabetes in East Asians: similarities and differences with populations in Europe and the United States. Annals of the New York Academy of Sciences [Internet]. 2013 [cited 2016 Jan 11]; 1281: 64-91. doi: 10.1111/nyas. 12098 .

3. Yoon KH, Lee JH, Kim JW, Cho JH, Choi YH, Ko $\mathrm{SH}$, Zimmet P, Son HY. Epidemic obesity and type 2 diabetes in Asia. Lancet [Internet]. 2006/11/14. 2006; 368: 1681-8. doi: S0140-6736(06)69703-1 [pii]10.1016/ S0140-6736(06)69703-1.

4. Gujral UP, Pradeepa R, Weber MB, Narayan KM, Mohan V. Type 2 diabetes in South Asians: similarities and differences with white Caucasian and other populations. Ann N Y Acad Sci [Internet]. 2013/01/16. 2013; 1281: 51-63. doi: 10.1111/j.1749-6632.2012.06838.x.

5. Kahn SE, Hull RL, Utzschneider KM. Mechanisms linking obesity to insulin resistance and type 2 diabetes. Nature [Internet]. 2006/12/15. 2006; 444: 840-6. doi: nature05482 [pii]10.1038/nature05482.

6. Beckman JA, Creager MA, Libby P. Diabetes and atherosclerosis: epidemiology, pathophysiology, and management. JAMA [Internet]. 2002/05/22. 2002; 287: 2570-81. doi: jrv10119 [pii].

7. Nolan CJ, Damm P, Prentki M. Type 2 diabetes across generations: from pathophysiology to prevention and management. Lancet [Internet]. 2011/06/28. 2011; 378: 169-81. doi: 10.1016/S01406736(11)60614-4S0140-6736(11)60614-4 [pii].

8. Hunink MG, Goldman L, Tosteson AN, Mittleman MA, Goldman PA, Williams LW, Tsevat J, Weinstein MC. The recent decline in mortality from coronary heart disease, 1980-1990. The effect of secular trends in risk factors and treatment. JAMA [Internet]. 1997/02/19. 1997; 277: 535-42. Available from http:/www.ncbi.nlm.nih.gov/ pubmed/9032159.

9. Ceylan-Isik AF, Fliethman RM, Wold LE, Ren J. Herbal and traditional Chinese medicine for the treatment of cardiovascular complications in diabetes mellitus. Curr Diabetes Rev [Internet]. 2008/11/11. 2008; 4: 320-8. Available from http://www.ncbi.nlm.nih.gov/ pubmed/18991600.

10. Li GQ, Kam A, Wong KH, Zhou X, Omar EA, Alqahtani A, Li KM, Razmovski-Naumovski V, Chan K. Herbal medicines for the management of diabetes. Adv Exp Med Biol [Internet]. 2013/02/09. 2012; 771: 396-413. Available from http://www.ncbi.nlm.nih.gov/pubmed/23393692.

11. Li WL, Zheng HC, Bukuru J, De Kimpe N. Natural medicines used in the traditional Chinese medical system for therapy of diabetes mellitus. J Ethnopharmacol [Internet]. 2004/04/22. 2004; 92: 1-21. doi: 10.1016/j.jep .2003.12.031S0378874104000315 [pii].

12. Chen FP, Chen TJ, Kung YY, Chen YC, Chou LF, Chen FJ, Hwang SJ. Use frequency of traditional 
Chinese medicine in Taiwan. BMC Health Serv Res [Internet]. 2007/02/27. 2007; 7: 26. doi: 1472-6963-7-26 [pii]10.1186/1472-6963-7-26.

13. Lee YC, Huang YT, Tsai YW, Huang SM, Kuo KN, McKee M, Nolte E. The impact of universal National Health Insurance on population health: the experience of Taiwan. BMC Health Serv Res [Internet]. 2010/08/05. 2010; 10: 225. doi: 10.1186/1472-6963-10-2251472-6963-10-225 [pii].

14. Huang TP, Liu PH, Lien AS, Yang SL, Chang HH, Yen HR. Characteristics of traditional Chinese medicine use in children with asthma: a nationwide population-based study. Allergy [Internet]. 2013/10/15. 2013; 68: 1610-3. doi: 10.1111/all.12273.

15. Lai JN, Wu CT, Wang JD. Prescription pattern of chinese herbal products for breast cancer in taiwan: a population-based study. Evid Based Complement Alternat Med [Internet]. 2012/06/12. 2012; 2012: 891893. doi: 10.1155/2012/891893.

16. Hsieh CF, Huang SL, Chen CL, Chen WT, Chang HC, Yang CC. Non-aristolochic acid prescribed Chinese herbal medicines and the risk of mortality in patients with chronic kidney disease: results from a population-based follow-up study. BMJ Open [Internet]. 2014/02/25. 2014; 4: e004033. doi: 10.1136/bmjopen-2013-004033bmjopen-2013-004033 [pii].

17. Huang CY, Tsai YT, Lai JN, Hsu FL. Prescription pattern of chinese herbal products for diabetes mellitus in taiwan: a population-based study. Evid Based Complement Alternat Med [Internet]. 2013/07/12. 2013; 2013: 201329. doi: $10.1155 / 2013 / 201329$.

18. Fang RC, Tsai YT, Lai JN, Yeh CH, Wu CT. The traditional chinese medicine prescription pattern of endometriosis patients in taiwan: a population-based study. Evid Based Complement Alternat Med [Internet]. 2012/10/12. 2012; 2012: 591391. doi: 10.1155/2012/591391.

19. Pan JC, Tsai YT, Lai JN, Fang RC, Yeh CH. The traditional Chinese medicine prescription pattern of patients with primary dysmenorrhea in Taiwan: a largescale cross sectional survey. J Ethnopharmacol [Internet]. 2014/01/15. 2014; 152: 314-9. doi: 10.1016/j.jep.2014.01 .002S0378-8741(14)00011-7 [pii].

20. Lin HC, Yang WC, Lee HC. Traditional Chinese medicine usage among schizophrenia patients. Complement Ther Med [Internet]. 2008/11/26. 2008; 16: 336-42. doi: 10.1016/j.ctim.2007.11.001S0965-2299(07)00113-6 [pii].

21. Li S, Culver B, Ren J. Benefit and risk of exercise on myocardial function in diabetes. Pharmacol Res [Internet]. 2003/06/12. 2003; 48: 127-32. doi: S1043661803000999 [pii].

22. Loke YK, Singh S, Furberg CD. Long-term use of thiazolidinediones and fractures in type 2 diabetes: a metaanalysis. CMAJ [Internet]. 2008/12/17. 2009; 180: 32-9. doi: 10.1503/cmaj.080486cmaj.080486 [pii].
23. Rao AD, Kuhadiya N, Reynolds K, Fonseca VA. Is the combination of sulfonylureas and metformin associated with an increased risk of cardiovascular disease or allcause mortality?: a meta-analysis of observational studies. Diabetes Care [Internet]. 2008/05/07. 2008; 31: 1672-8. doi: $10.2337 / \mathrm{dc} 08-0167 \mathrm{dc} 08-0167$ [pii].

24. Roumie CL, Hung AM, Greevy RA, Grijalva CG, Liu X, Murff HJ, Elasy TA, Griffin MR. Comparative effectiveness of sulfonylurea and metformin monotherapy on cardiovascular events in type 2 diabetes mellitus: a cohort study. Ann Intern Med [Internet]. 2012/11/07. 2012; 157: 601-10. doi: 10.7326/0003-4819-157-9-201211060000031389845 [pii].

25. Lincoff AM, Wolski K, Nicholls SJ, Nissen SE. Pioglitazone and risk of cardiovascular events in patients with type 2 diabetes mellitus: a meta-analysis of randomized trials. JAMA [Internet]. 2007/09/13. 2007; 298: 1180-8. doi: 298/10/1180 [pii]10.1001/jama.298.10.1180.

26. Singh S, Loke YK, Furberg CD. Long-term use of thiazolidinediones and the associated risk of pneumonia or lower respiratory tract infection: systematic review and meta-analysis. Thorax [Internet]. 2011/02/18. 2011; 66: 383-8. doi: 10.1136/thx.2010.152777thx.2010.152777 [pii].

27. Turner RM, Kwok CS, Chen-Turner C, Maduakor CA, Singh S, Loke YK. Thiazolidinediones and associated risk of Bladder Cancer: a Systematic Review and Meta-analysis. Br J Clin Pharmacol [Internet]. 2013/12/12. 2013;. doi: 10.1111/bcp.12306.

28. Konstantinidis K, Whelan RS, Kitsis RN. Mechanisms of cell death in heart disease. Arteriosclerosis, thrombosis, and vascular biology [Internet]. 2012 [cited 2016 Feb 17]; 32: 1552-62. doi: 10.1161/ATVBAHA.111.224915.

29. Whelan RS, Kaplinskiy V, Kitsis RN. Cell death in the pathogenesis of heart disease: mechanisms and significance. Annual review of physiology [Internet]. 2010 [cited 2016 Feb 7]; 72: 19-44. doi: 10.1146/annurev. physiol.010908.163111.

30. Kim D-E, Kim B, Shin H-S, Kwon HJ, Park E-S. The protective effect of hispidin against hydrogen peroxideinduced apoptosis in $\mathrm{H} 9 \mathrm{c} 2$ cardiomyoblast cells through Akt/GSK-3 $\beta$ and ERK1/2 signaling pathway. Experimental cell research [Internet]. 2014 [cited 2016 Feb 17]; 327: 264-75. doi: 10.1016/j.yexcr.2014.07.037.

31. Park E-S, Kang JC, Kang D-H, Jang YC, Yi KY, Chung H-J, Park JS, Kim B, Feng Z-P, Shin H-S. 5-AIQ inhibits $\mathrm{H} 2 \mathrm{O} 2$-induced apoptosis through reactive oxygen species scavenging and Akt/GSK-3 $\beta$ signaling pathway in H9c2 cardiomyocytes. Toxicology and Applied Pharmacology [Internet]. 2013 [cited 2016 Jan 11]; 268: 90-8. doi: 10.1016/j.taap.2013.01.004.

32. Park E-S, Kang JC, Jang YC, Park JS, Jang SY, Kim D-E, Kim B, Shin H-S. Cardioprotective effects of rhamnetin in $\mathrm{H} 9 \mathrm{c} 2$ cardiomyoblast cells under $\mathrm{H}_{2} \mathrm{O}_{2}$-induced apoptosis. Journal of ethnopharmacology [Internet]. 2014 [cited 2016 Feb 17]; 153: 552-60. doi: 10.1016/j.jep.2014.02.019. 
33. Gao Z, Xu H, Shi D, Wen C, Liu B. Analysis on outcome of 5284 patients with coronary artery disease: The role of integrative medicine. Journal of Ethnopharmacology [Internet]. 2012; 141: 578-83. doi: 10.1016/j. jep.2011.08.071.

34. Tam WY, Chook P, Qiao M, Chan LT, Chan TYK, Poon YK, Fung KP, Leung PC, Woo KS. The efficacy and tolerability of adjunctive alternative herbal medicine (Salvia miltiorrhiza and Pueraria lobata) on vascular function and structure in coronary patients. Journal of alternative and complementary medicine [Internet]. 2009; 15: 415-21. doi: 10.1089/acm.2008.0400.

35. Li YQ, Jin M, Qiu SL, Wang PL, Zhu TG, Wang CL, Li TC, Liu HX, Bian H, Yao LF, Shi DZ. Effect of Chinese drugs for supplementing Qi, nourishing yin and activating blood circulation on myocardial perfusion in patients with acute myocardial infarction after revascularization. Chinese Journal of Integrative Medicine. 2009; 15: 19-25. doi: 10.1007/s11655-009-0019-7.

36. Liu HY, Wang W, Shi DZ, Ge JB, Zhang L, Peng J, Wang CL, Wang PL. Protective effect of Chinese herbs for supplementing qi, nourishing yin and activating blood circulation on heart function of patients with acute coronary syndrome after percutaneous coronary intervention [Internet]. Chinese Journal of Integrative Medicine. 2012. p. 423-30. doi: http://dx.doi.org/10.1007/s11655-012-0966-5.

37. Grant SJ, Chang DH-T, Liu J, Wong V, Kiat H, Bensoussan A. Chinese herbal medicine for impaired glucose tolerance: a randomized placebo controlled trial. BMC complementary and alternative medicine [Internet]. 2013 [cited 2016 Feb 19]; 13: 104. doi: 10.1186/1472-6882-13-104.

38. Lian F, Li G, Chen X, Wang X, Piao C, Wang J, Hong Y, Ba Z, Wu S, Zhou X, Lang J, Liu Y, Zhang R, et al. Chinese herbal medicine Tianqi reduces progression from impaired glucose tolerance to diabetes: a double-blind, randomized, placebo-controlled, multicenter trial. J Clin Endocrinol Metab [Internet]. 2014/01/18. 2014; 99: 648-55. doi: 10.1210/jc.2013-3276.

39. Prabhakar PK, Doble M. Mechanism of action of natural products used in the treatment of diabetes mellitus. Chinese journal of integrative medicine [Internet]. 2011 [cited 2016 Feb 19]; 17: 563-74. doi: 10.1007/s11655-011-0810-3.

40. Yang P-R, Liang H-F, Chu Y-H, Chen P-C, Lin Y-Y. Frequencies and prescription patterns of traditional Chinese medicine use among elderly patients in Taiwan: A population-based study. Journal of ethnopharmacology [Internet]. 2015 [cited 2016 Feb 22]; 169: 328-34. doi: 10.1016/j.jep.2015.04.046.

41. Liao H-H, Yeh C-C, Lin C-C, Chen B-C, Yeh M-H, Chang K-M, Sun M-F, Yen H-R. Prescription patterns of Chinese herbal products for patients with fractures in Taiwan: A nationwide population-based study. Journal of ethnopharmacology [Internet]. 2015 [cited 2016 Feb 21]; 173: 11-9. doi: 10.1016/j.jep.2015.07.014.
42. Tsai Y-T, Lai J-N, Wu C-T. The use of Chinese herbal products and its influence on tamoxifen induced endometrial cancer risk among female breast cancer patients: a population-based study. Journal of ethnopharmacology [Internet]. 2014 [cited 2016 Feb 21]; 155: 1256-62. doi: 10.1016/j.jep.2014.07.008.

43. Kanai S, Taniguchi N, Higashino H. Study of sokeikakketu-to (shu-jing-huo-xue-tang) in adjuvant arthritis rats. The American journal of Chinese medicine [Internet]. 2003 [cited 2016 Feb 21]; 31: 879-84. doi: 10.1142/ S0192415X03001600.

44. Shu H, Arita H, Hayashida M, Zhang L, An K, Huang W, Hanaoka K. Anti-hypersensitivity effects of Shu-jing-huoxue-tang, a Chinese herbal medicine, in CCI-neuropathic rats. Journal of ethnopharmacology [Internet]. 2010 [cited 2016 Feb 21]; 131: 464-70. doi: 10.1016/j.jep.2010.07.004.

45. Sun D-D, Xu X-F, Cui J-C, Song X-M, Li X. [Analysis on chemical components from water extract of paeoniae radix alba by high performance liquid chromatographyelectrospray ionization-quadrupole-time of flight-mass spectrometry]. Zhongguo Zhong yao za zhi = Zhongguo zhongyao zazhi $=$ China journal of Chinese materia medica [Internet]. 2013 [cited 2016 Nov 17]; 38: 1760-5. Available from http://www.ncbi.nlm.nih.gov/pubmed/24010292.

46. Gan P, Zhong M, Huang X, Sun M, Wang Y, Xiao Y, Zeng C, Yuan Q, Liu Z, Zhou H. Pharmacokinetic comparisons of albiflorin and paeoniflorin after oral administration of Shaoyao-Gancao-Tang and single herb Paeony decoction to rats. Planta medica [Internet]. 2012 [cited 2016 Nov 16]; 78: 237-43. doi: 10.1055/s-0031-1280366.

47. Gong C, Yang H, Wei H, Qi C, Wang C. Pharmacokinetic comparisons by UPLC-MS/MS of isomer paeoniflorin and albiflorin after oral administration decoctions of single-herb Radix Paeoniae Alba and Zengmian Yiliu prescription to rats. Biomedical Chromatography [Internet]. 2015 [cited 2016 Nov 16]; 29: 416-24. doi: 10.1002/bmc.3292.

48. Wang Y, Xu C, Wang P, Lin X, Yang Y, Li D, Li H, Wu $\mathrm{X}$, Liu H. Pharmacokinetic comparisons of different combinations of Shaoyao-Gancao-Decoction in rats: Simultaneous determination of ten active constituents by HPLC-MS/MS. Journal of Chromatography B [Internet]. 2013 [cited 2016 Nov 16]; 932: 76-87. doi: 10.1016/j. jchromb.2013.06.021.

49. Xu C-H, Wang P, Wang Y, Yang Y, Li D-H, Li H-F, Sun S-Q, Wu X-Z. Pharmacokinetic comparisons of two different combinations of Shaoyao-Gancao Decoction in rats: Competing mechanisms between paeoniflorin and glycyrrhetinic acid. Journal of Ethnopharmacology [Internet]. 2013 [cited 2016 Nov 16]; 149: 443-52. doi: 10.1016/j.jep.2013.06.049.

50. Kim ID, Ha BJ. Paeoniflorin protects RAW 264.7 macrophages from LPS-induced cytotoxicity and genotoxicity. Toxicology in vitro [Internet]. 2009 [cited 2016 Nov 18]; 23: 1014-9. doi: 10.1016/j.tiv.2009.06.019. 
51. Dong H, Li R, Yu C, Xu T, Zhang X, Dong M. Paeoniflorin inhibition of 6-hydroxydopamine-induced apoptosis in PC12 cells via suppressing reactive oxygen speciesmediated $\mathrm{PKC} \delta / \mathrm{NF}-\kappa \mathrm{B}$ pathway. Neuroscience [Internet]. 2015 [cited 2016 Nov 18]; 285: 70-80. doi: 10.1016/j. neuroscience.2014.11.008.

52. Zhang T, Yang Z, Yang S, Du J, Wang S. Immunoregulatory Effects of Paeoniflorin Exerts Anti-asthmatic Effects via Modulation of the Th1/Th2 Equilibrium. Inflammation [Internet]. 2015 [cited 2016 Nov 18]; 38: 2017-25. doi: 10.1007/s10753-015-0182-5.

53. Liu D-Z, Xie K-Q, Ji X-Q, Ye Y, Jiang C-L, Zhu X-Z. Neuroprotective effect of paeoniflorin on cerebral ischemic rat by activating adenosine $\mathrm{A}$, receptor in a manner different from its classical agonists. British Journal of Pharmacology [Internet]. 2005 [cited 2016 Nov 18]; 146: 604-11. doi: 10.1038/sj.bjp.0706335.

54. Chen C, Du P, Wang J. Paeoniflorin ameliorates acute myocardial infarction of rats by inhibiting inflammation and inducible nitric oxide synthase signaling pathways. Molecular medicine reports [Internet]. 2015 [cited 2016 Nov 18]; 12: 3937-43. doi: 10.3892/mmr.2015.3870.

55. Qian G-Q, Ding J, Zhang X, Yin X, Gao Y, Zhao G-P. Preconditioning with glycyrrhizic, ferulic, paeoniflorin, cinnamic prevents rat hearts from ischemia/reperfusion injury via endothelial nitric oxide pathway. Pharmacognosy magazine [Internet]. [cited 2016 Nov 18]; 11: 292-6. doi: 10.4103/0973-1296.153081.

56. Han F, Zhou D, Yin X, Sun Z, Han J, Ye L, Zhao W, Zhang Y, Wang Z, Zheng L. Paeoniflorin protects diabetic mice against myocardial ischemic injury via the transient receptor potential vanilloid 1/calcitonin gene-related peptide pathway. Cell \& Bioscience [Internet]. 2016 [cited 2016 Nov 18]; 6: 37. doi: 10.1186/s13578-016-0085-7.

57. Jeong SY, Kim HM, Lee KH, Kim KY, Huang DS, Kim JH, Seong RS. Quantitative Analysis of Marker Compounds in \&lt;i\&gt;Angelica gigas\&lt;/igt; \&lt;i\&gt;Angelica sinensis\&lt;/i\&gt; $\quad$ and \&lt;i\&gt;Angelica acutiloba\&lt;/i\&gt; by HPLC/DAD. CHEMICAL \& PHARMACEUTICAL BULLETIN [Internet]. 2015 [cited 2016 Nov 16]; 63: 504-11. doi: 10.1248/cpb.c15-00081.

58. Zhao Y, Sun J, Yu LL, Chen P. Chromatographic and mass spectrometric fingerprinting analyses of Angelica sinensis (Oliv.) Diels-derived dietary supplements. Analytical and Bioanalytical Chemistry [Internet]. 2013 [cited 2016 Nov 16]; 405: 4477-85. doi: 10.1007/s00216-012-6668-1.

59. Suzuki A, Yamamoto M, Jokura H, Fujii A, Tokimitsu I, Hase T, Saito I. Ferulic acid restores endothelium-dependent vasodilation in aortas of spontaneously hypertensive rats. American journal of hypertension [Internet]. 2007 [cited 2016 Nov 18]; 20: 508-13. doi: 10.1016/j. amjhyper.2006.11.008

60. Srinivasan M, Sudheer AR, Menon VP. Ferulic Acid: therapeutic potential through its antioxidant property. Journal of clinical biochemistry and nutrition [Internet].
2007 [cited 2016 Nov 18]; 40: 92-100. doi: 10.3164/ jcbn.40.92.

61. Wang B-H, Ou-Yang J-P. Pharmacological actions of sodium ferulate in cardiovascular system. Cardiovascular drug reviews [Internet]. 2005 [cited 2016 Nov 18]; 23: 161-72. Available from http://www.ncbi.nlm.nih.gov/ pubmed/16007232.

62. Alam MA, Sernia C, Brown L. Ferulic Acid Improves Cardiovascular and Kidney Structure and Function in Hypertensive Rats. Journal of Cardiovascular Pharmacology [Internet]. 2013 [cited 2016 Nov 18]; 61: 240-9. doi: 10.1097/FJC.0b013e31827cb600.

63. Chou S-C, Everngam MC, Sturtz G, Beck JJ. Antibacterial activity of components fromLomatium californicum. Phytotherapy Research [Internet]. 2006 [cited 2016 Nov 18]; 20: 153-6. doi: 10.1002/ptr.1828.

64. Li S-Y, Yu Y, Li S-P. Identification of antioxidants in essential oil of radix Angelicae sinensis using HPLC coupled with DAD-MS and ABTS-based assay. Journal of agricultural and food chemistry [Internet]. 2007 [cited 2016 Nov 18]; 55: 3358-62. doi: 10.1021/jf070140t.

65. Hinoshita F, Ogura Y, Suzuki Y, Hara S, Yamada A, Tanaka N, Yamashita A, Marumo F. Effect of orally administered shao-yao-gan-cao-tang (Shakuyaku-kanzo-to) on muscle cramps in maintenance hemodialysis patients: a preliminary study. The American journal of Chinese medicine [Internet]. 2003 [cited 2016 Feb 22]; 31: 445-53. doi: 10.1142/ S0192415X03001144.

66. Suganami A, Sakamoto K, Ono T, Watanabe H, Hijioka N, Murakawa M, Kimura J. The inhibitory effect of shakuyakukanzoto on $\mathrm{K}+$ current in $\mathrm{H} 9 \mathrm{c} 2$ cells. Fukushima journal of medical science [Internet]. 2014 [cited 2016 Feb 22]; 60: 22-30. Available from http://www.ncbi.nlm.nih. gov/pubmed/24670676.

67. Du D, Yan J, Ren J, Lv H, Li Y, Xu S, Wang Y, Ma S, Qu J, Tang W, Hu Z, Yu S. Synthesis, Biological Evaluation, and Molecular Modeling of Glycyrrhizin Derivatives as Potent High-Mobility Group Box-1 Inhibitors with Anti-HeartFailure Activity in vivo. Journal of Medicinal Chemistry [Internet]. 2013 [cited 2016 Nov 18]; 56: 97-108. doi: 10.1021/jm301248y.

68. Parisella ML, Angelone T, Gattuso A, Cerra MC, Pellegrino D. Glycyrrhizin and glycyrrhetinic acid directly modulate rat cardiac performance. The Journal of Nutritional Biochemistry [Internet]. 2012 [cited 2016 Nov 18]; 23: 69-75. doi: 10.1016/j.jnutbio.2010.10.011.

69. Zhang H, Song Y, Zhang Z. Glycyrrhizin Administration Ameliorates Coxsackievirus B3-Induced Myocarditis in Mice. The American Journal of the Medical Sciences [Internet]. 2012 [cited 2016 Nov 18]; 344: 206-10. doi: 10.1097/MAJ.0b013e31823e2867.

70. Zhai C, Zhang M, Zhang Y, Xu H, Wang J, An G, Wang Y, Li L. Glycyrrhizin protects rat heart against ischemiareperfusion injury through blockade of HMGB1-dependent phospho-JNK/Bax pathway. Acta Pharmacologica Sinica 
[Internet]. 2012 [cited 2016 Nov 18]; 33: 1477-87. doi: 10.1038/aps.2012.112.

71. Haleagrahara N, Varkkey J, Chakravarthi S. Cardioprotective Effects of Glycyrrhizic Acid Against Isoproterenol-Induced Myocardial Ischemia in Rats. International Journal of Molecular Sciences [Internet]. 2011 [cited 2016 Nov 18]; 12: 7100-13. doi: 10.3390/ ijms12107100.

72. Eu C, Lim W, Ton S, Kadir K. Glycyrrhizic acid improved lipoprotein lipase expression, insulin sensitivity, serum lipid and lipid deposition in high-fat diet-induced obese rats. Lipids in Health and Disease [Internet]. 2010 [cited 2016 Nov 18]; 9: 81. doi: 10.1186/1476-511X-9-81.

73. Lin Y-H, Chen Y-C, Tseng Y-H, Lin M-H, Hwang S-J, Chen T-J, Chou L-F. Trend of urban-rural disparities in hospice utilization in Taiwan. PloS one [Internet]. 2013 [cited 2016 Mar 2]; 8: e62492. doi: 10.1371/journal.pone.0062492. 